\title{
DUAL LOCAL DRUG DELIVERY OF VANCOMYCIN AND FARNESOL FOR MITIGATION OF MRSA INFECTION IN VIVO - A PILOT STUDY
}

\author{
U.C. Woelfle ${ }^{1,2}$, T. Briggs ${ }^{3}$, S. Bhattacharyya ${ }^{3}$, H. Qu $^{3}$, N. Sheth ${ }^{4}$, C. Knabe ${ }^{1, \$, *}$ and P. Ducheyne ${ }^{3, \$}$ \\ ${ }^{1}$ Department of Experimental Orofacial Medicine, Philipps University, Marburg, Germany \\ ${ }^{2}$ Department of Conservative Dentistry and Periodontology, University Hospital, LMU Munich, \\ Munich, Germany \\ ${ }^{3}$ Department of Bioengineering, University of Pennsylvania, Philadelphia, USA \\ ${ }^{4}$ Department of Orthopaedic Surgery, University of Pennsylvania, Philadelphia, USA \\ $\S$ These authors contributed equally to this work
}

\begin{abstract}
Surgical site infections after orthopaedic surgery using fracture fixation devices or endosseous implants create major surgical challenges with severe adverse effects, such as osteomyelitis. These infections are frequently caused by Staphylococcus aureus, often with high resistance to antibiotics, such as methicillinresistant Staphylococcus aureus (MRSA). Due to the formation of impenetrable biofilms on implant surfaces, systemic antibiotic treatment has become exceedingly difficult. New solutions are pursued by combining several drugs using a controlled delivery system from specifically engineered implant surfaces. A sol-gel coating on titanium implants was previously developed with $20 \mathrm{wt} \%$ vancomycin and 30 wt \% farnesol, with suppression of MRSA in vitro. The present study investigated the efficacy of sol-gel film coatings for controlled dual local delivery over 4 weeks utilising a rat infection model. The findings confirmed the viability of this new concept in vivo based on the differences observed between coatings containing vancomycin alone (SGV) and the dual-drug-containing coating with vancomycin and farnesol (SGVF). While both the SGVF and SGV coatings facilitated excellent preservation of the osseous microarchitecture, SGVF coating displayed a slightly higher potency for suppressing MRSA infiltration than SGV, in combination with a lower reactive bone remodelling activity, most likely by disturbing biofilm formation. The next step for advancing the concept of dual-drug delivery from sol-gel coatings to the clinic and confirming the promising effect of the SGVF coatings on reactive bone remodelling and suppressing MRSA infiltration is a study in a larger animal species with longer time points.
\end{abstract}

Keywords: Antimicrobial coating, controlled local drug delivery, silica sol-gel, vancomycin, farnesol, methicillin-resistant Staphylococcus aureus, in vivo, osteomyelitis, $\mu \mathrm{CT}$, histology.

*Address for correspondence: Prof. Christine Knabe, Department of Experimental and Orofacial Medicine, School of Dental Medicine, Philipps University, Georg-Voigt-Str. 3, 35039 Marburg, Germany.

Telephone number: +4964215863600 Email: knabec@med.uni-marburg.de

Copyright policy: This article is distributed in accordance with Creative Commons Attribution Licence (http://creativecommons.org/licenses/by-sa/4.0/).

\begin{tabular}{|c|c|c|c|}
\hline & List of Abbreviations & $\mu \mathrm{CT}$ & micro-computed tomography \\
\hline & & $\mathrm{MIC}$ & minimum inhibitory concentration \\
\hline $2 \mathrm{D}$ & two dimensional & MRSA & methicillin-resistant $S$. aureus \\
\hline $3 \mathrm{D}$ & three dimensional & $\mathrm{OC}$ & osteocalcin \\
\hline ALP & alkaline phosphatase & PDLLA & poly(D,L-lactic acid) \\
\hline BSP & bone sialoprotein & PMMA & polymethylmethacrylate \\
\hline $\mathrm{BV} / \mathrm{TV}$ & bone volume per total volume & RT & room temperature \\
\hline CFU & colony-forming unit & S. aureus & Staphylococcus aureus \\
\hline COL I & type I collagen & SG & sol-gel \\
\hline FDA & Food and Drug Administration & SGV & SG coating containing vancomycin \\
\hline HPLC & $\begin{array}{l}\text { high performance liquid } \\
\text { chromatography }\end{array}$ & SGVF & $\begin{array}{l}\text { SG coating containing vancomycin } \\
\text { and farnesol }\end{array}$ \\
\hline $\mathrm{HU}$ & Hounsfield unit & SSI & surgical site infections \\
\hline
\end{tabular}


TRAP tartrate-resistant acid phosphatase staining

TRI

TSB

triangulation of surfaces

trypticase soy broth

\section{Introduction}

S. aureus, a widespread Gram-positive coccal bacterium, is both a harmless commensal commonly present on the mucosal surfaces of the nose, respiratory tract as well as on the skin, as well as a devastating pathogen causing serious human infections, such as dermal infections, pneumonia, septicaemia, SSI and contaminated open fractures (Lew and Waldvogel, 2004; Parsons and Strauss, 2004). In addition, SSI are most frequently caused by MRSA (Schmidt et al., 2014; Tiemann et al., 2014; Tiemann, 2017), lead to major surgical failures (Parsons and Strauss, 2004; Tiemann, 2017; Walter et al., 2012) and are associated with an estimated mortality rate of $5 \%$ (Sganga et al., 2017). Although the use of fracture-fixation devices or endosseous implants is often needed, they also constitute a major factor favouring the development and propagation of infections (Fraimow, 2009; Lew and Waldvogel, 2004; Tiemann, 2017) due to bacterial colonisation and formation of impenetrable biofilms on the implant surface (Gristina and Costerton, 1985; Gristina et al., 1985; Khardori and Yassien, 1995; Stewart, 2002). Biofilms consist of communities of bacteria that attach to the biomaterial surface, encasing themselves in an extracellular polysaccharide matrix. Such a matrix contains a multitude of proteins which govern bacterial attachment to the implant surface as wells as the different stages of biofilm formation (Speziale et al., 2014). In this environment, S. aureus can evade the host response and enter a long-lasting dormant state, which impairs the delivery and function of antibiotics (Gristina and Costerton, 1985; Gristina et al., 1985; Thammavongsa et al., 2015).

Due to the widespread use of antibiotics and bacterial evolution, antibiotic-resistant strains, such as MRSA, have emerged in recent years that display a significant resistance to beta-lactam antibiotics including penicillins and cephalosporins. Multiple resistance, even to the commonly used vancomycin, has been described (Hiramatsu et al., 1997a; Hiramatsu et al., 1997b; Sieradzki et al., 1999). The development of resistance poses a major obstacle to infection eradication and therapeutic success. This is even more true when a biofilm is present (Stewart, 2002). As a result, MRSA infections represent a considerable challenge and have been shown to be responsible for numerous healthcare-associated infections. The US Centers for Disease Control and Prevention reported 80,000 invasive MRSA infections, 157,000 SSIs and 11,285 related deaths in 2011 (Avery et al., 2015).

Key treatment principles for SSI are thorough debridement involving extensive surgical revision, with removal of the osteosynthesis material, and

appropriate antibiotic coverage using systemic or local administration in accordance with the range of bacterial species present (Fraimow, 2009; Parsons and Strauss, 2004; Tiemann, 2017). The success of antibiotic regimens and avoiding antibiotic resistance is dependent upon the right selection of antibiotics based on species, resistance, concentration and duration. With systemic administration, it is often difficult to achieve a sufficient concentration in the affected bone tissue due to a diffusion gradient in uninfected bones, with an estimated bone to serum relation of $0.57 \pm 0.2 \mu \mathrm{g} / \mathrm{mL}$ (Massias et al., 1992). This is even more applicable within biofilms. At the same time, sufficient attention needs to be devoted to avoiding any risk of nephrotoxicity associated with high doses of antibiotics (Kollef, 2007; Walter et al., 2012). Consequently, novel therapeutic concepts have focussed on combining several therapeutic agents in addition to using controlled local drug delivery concepts such as bone cements, polymer sponges and antibiotic-loaded PMMA beads (Adams et al., 1992; Cancienne et al., 2015; Lalidou et al., 2014; Lucke et al., 2003a). However, it must be pointed out that local delivery concepts usually feature a burst release and often require an additional surgical intervention for their removal due to their lack of biocompatibility (Stemberger et al., 1997). Antibiotic-loaded implant coatings, such as the biodegradable gentamycinPDLLA PROtect ${ }^{\mathrm{TM}}$ coating on titanium implants (Lucke et al., 2003a; Lucke et al., 2005; Schmidmaier et al., 2006; Vester et al., 2010), have been successfully used on tibial nails for infection prophylaxis (Fuchs et al., 2011).

Silica SG coatings on metallic implants feature nanostructure-based controlled release and possess osteogenic qualities (Santos et al., 1999). They are highly porous, show excellent biocompatibility in vivo and allow for the incorporation of heat-sensitive molecules such as antibiotics, growth factors and antibodies due to their synthesis at RT (Aughenbaugh et al., 2001; Catauro et al., 2014; Radin et al., 2013; Radin et al., 2001; Radin et al., 2005). The SG process leads to a smooth surface that is less prone to biofilm attachment (Braem et al., 2014) and results in homogeneous distribution of the incorporated molecules in the SG film, which facilitates specifically tailored, predictable quasi-zero-order release profiles over an extended time (Radin and Ducheyne, 2007). Silica SG-coated Ti-alloy rods releasing vancomycin are able to prevent $S$. aureus-induced SSI and osteomyelitis in rats (Adams et al., 2009). The present study employed a silica SG surface to contain the combination of vancomycin and farnesol (Aughenbaugh et al., 2001; Bhattacharyya et al., 2014; Radin et al., 2013; Radin et al., 2001) to address SSI caused by MRSA. Vancomycin is the first-line antibiotic used for treating MRSA (Fraimow, 2009). Farnesol, a quorum-sensing alcohol, is an acyclic sesquiterpene alcohol, which effectively inhibits $S$. aureus growth in vitro by increasing the permeability of bacterial walls (Jabra-Rizk et al., 2006; Kaneko et al., 
2011). Farnesol is FDA-approved as a food additive (section 21CFR172.515). A synergistic effect between farnesol and gentamycin is demonstrated in vitro (Jabra-Rizk et al., 2006) as well as a potentiation of the activity of $\beta$-lactam antibiotics by farnesol, whereas farnesol has been shown to have poor antibacterial activity on its own (Kim et al., 2018). Other studies have suggested a positive synergistic effect when combining farnesol with vancomycin (Pammi et al., 2011). Bhattacharyya et al. (2014) have previously demonstrated the therapeutic potential of controlled dual delivery of vancomycin and farnesol from silica SG coatings and the efficacy of the combined release of vancomycin and farnesol against MRSA in vitro. Best results were achieved for SG coatings containing $20 \mathrm{wt} \%$ vancomycin and $30 \mathrm{wt} \%$ farnesol. Since then, farnesol has also been deposited on titanium alloy implant surfaces for use in vivo (Constantino et al., 2016).

The aim of the present study was to evaluate the efficacy of the silica SG coating on titanium alloy pins (Ti-6Al-4V) with respect to the dual local controlled delivery of vancomycin and farnesol in vivo. To this end, a previously established rat femoral infection model was utilised (Adams et al., 2009; Lucke et al., 2003b), employing HCT, histological and immunohistochemical analysis of S. aureus and TRAP-positive osteoclasts. Osteogenic marker expression was assessed in the cell and matrix components of the bone tissue to analyse and characterise MRSA-induced bone infection, osteomyelitis and concomitant changes in the bone tissue and osseous microarchitecture. The present study tested the hypothesis that controlled release of vancomycin and farnesol may have a greater bactericidal effect when treating MRSA infection than the controlled release of vancomyin alone.

\section{Materials and Methods}

\section{SG-coated implants}

The SG process, with the fabrication of SG coatings on metal implants, was reported on in detail previously (Radin and Ducheyne, 2007). In brief, Ti$6 \mathrm{Al}-4 \mathrm{~V}$ titanium alloy rods with $1.25 \mathrm{~mm}$ diameter and $20 \mathrm{~mm}$ length were prepared using optimised procedures described in full elsewhere (Adams et al., 2009; Bhattacharyya et al., 2014; Radin et al., 2007). It included sandblasting (Korox ${ }^{\circledR} 50(50 \mu \mathrm{m}), 46062$, BEGO, Bremen, Germany) at $276 \mathrm{kPa}$ (SandStorm Expert, Vaniman, Murrieta, CA, USA) for optimised surface adhesion of the SG (Qu et al., 2015; Radin and Ducheyne, 2007), cleaning by sonification with acetone (30 min), 2× LIQUINOX detergent $(1 \mathrm{~h})$ (Electron MicroscopyScience, Hatfield, PA, USA) and rinsing with distilled water.

After further sonification with $35 \%$ nitric acid solution $(1 \mathrm{~h})$ and rinsing with distilled water, rods were dried for at least $1 \mathrm{~d}$. For single-step acid-catalysed SG synthesis, $2.16 \mathrm{~mL}$ distilled water, $0.25 \mathrm{~mL}$
$1 \mathrm{~mol} / \mathrm{L} \mathrm{HCl}$ (Fisher Scientific) and $9.63 \mathrm{~mL} 100 \%$ ethanol were added to the rods ( $5 \mathrm{~min}) .5 \mathrm{~mL}$ tetraethyl-orthosilicate was added dropwise while stirring at $5 \mathrm{~Hz}$. After stirring for $2 \mathrm{~h}, 20 \%$ wt vancomycin (Lederle Inc., Carolina, Puerto Rico) and $30 \% \mathrm{wt}$ farnesol (Lederle Inc.) were added (Fig. 1) to the solution followed by stirring for another $30 \mathrm{~min}$. The implant coating was applied by dipping, utilising a Velmex NF90 series stepping motor (Velmex, Inc., Bloomfield, NJ, USA), with a controlled vertically mounted gliding unit with the withdrawal speed set at $0.569 \mathrm{~mm} / \mathrm{s}$, creating 15 layers (one dipping per layer). Each layer was individually air-dried for $2 \mathrm{~h}$ and the entire coating for at least $12 \mathrm{~h}$. Qu et al. (2014) have previously shown that a coating consisting of 15 layers yielded the required release properties. The weight of the coating was measured using a scale with precision and sensitivity $\leq 0.01 \mathrm{mg}$. Ellipsometry confirmed the thickness (helium-neon laser source, $632.8 \mathrm{~nm}$, AutoEL II, Rudolf Research Analytical, Flanders, NJ, USA). The surface integrity was confirmed by optical microscopy (400× magnification) in combination with a high-resolution video camera. To verify the controlled release of the drugs for up to 4 weeks, the concentrations of released vancomycin and farnesol were measured spectrophotometrically at $281 \mathrm{~nm}$ (Ultrospec Plus UV/Vis Spectrophotometer, Pharmacia Biotech LKB, Piscataway, NJ, USA) and by HPLC at $215 \mathrm{~nm}$, as described previously (Bhattacharyya et al., 2014).

\section{S. aureus}

One mature MRSA colony (ATCC 33591, MIC for vancomycin $16 \mu \mathrm{g} / \mathrm{mL}$, American Type Culture Collection) was collected from a bacterial plate using a sterile inoculating loop, aseptically transferred into a test tube containing $5 \mathrm{~mL}$ sterile TSB (BBL Microbiology Systems, Cockeysville, MD, USA) and incubated on a shaker at $37^{\circ} \mathrm{C}$ for $18 \mathrm{~h}$. For every rat, $150 \mu \mathrm{L}$ suspension of $10^{3}$ CFU MRSA in TSB was freshly prepared and the concentration was confirmed using a spectrophotometer at $625 \mathrm{~nm}$ (Ultrospec Plus UV/ Vis Spectrophotometer, Pharmacia Biotech LKB).

\section{Animal model}

The animal model utilised in the present study was described in detail before (Adams et al., 2009). In brief, male adult Sprague-Dawley rats (Charles River) 12 weeks old (average weight 355 g) were anaesthetised using $2 \%$ isoflurane gas. The right knee joint was shaved and disinfected with betadine. Subsequently, the femoral canal was reamed from the knee joint through a percutaneous stab incision $25 \mathrm{~mm}$ deep, first with a $20 \mathrm{G}$, then with an $18 \mathrm{G}$ needle, followed by injection of $150 \mu \mathrm{L}$ of the MRSA inoculum (Adams et al., 2009). Depending on the experimental group (Fig. 1a), a pin with either SG coating without addition of any drugs (SG), SG coating containing vancomycin (SGV) or SG coating containing vancomycin and farnesol (SGVF) was implanted in press-fit mode into the canal, i.e. without 
any cement. The stab incision was closed using fibrin glue. The left leg was left uninfected and without surgical intervention or implant as internal control.

In order to simulate the systemic antibiotic therapy commonly applied in patients, the rats in the intravenous reference groups received a SG-coated implant in combination with $100 \mu \mathrm{L}$ of $0.4 \mathrm{mg} / \mathrm{mL}$ or $4 \mathrm{mg} / \mathrm{mL}$ vancomycin intravenously (Vanc IV) into the tail vein immediately after conclusion of the surgery and once daily for $3 \mathrm{~d}$ post-surgery (Lemaire et al., 2008; Probst et al., 2006). All animals of the
$0.4 \mathrm{mg} / \mathrm{mL}$ Vanc IV group had to be sacrificed after 2 weeks, since the severity of the osteomyelitis led to an unbearable condition for the animals. As a result, the 10 -fold higher, $4 \mathrm{mg} / \mathrm{mL}$ Vanc IV group was used as the intravenous reference group at 2 and 4 weeks. No additional systemic administration of antibiotics was provided. The animals were housed under a $12 \mathrm{~h}$ light/dark cycle at $24 \pm 2{ }^{\circ} \mathrm{C}$, relative humidity of $60 \pm 10 \%$ and received fresh food daily as well as water ad libitum. After 2 or 4 weeks, the animals were weighed, sacrificed and both femora were harvested, a

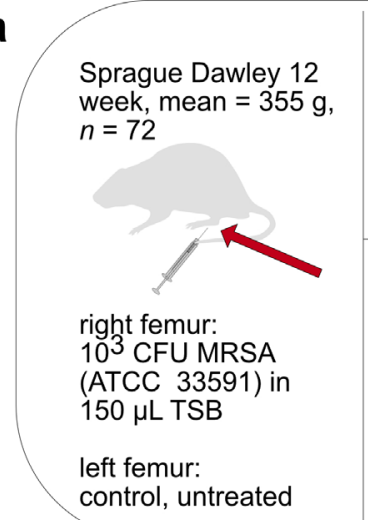

$\mathrm{SG}+0.4 \mathrm{mg} / \mathrm{mL}$ Vanc IV

2 weeks, $n=8$ ( $n=5 \mu \mathrm{CT}, n=3$ histo)

$\mathrm{SG}+4 \mathrm{mg} / \mathrm{mL}$ Vanc IV

2 weeks, $n=8(n=5 \mu \mathrm{CT}, n=3$ histo $)$

4 weeks, $n=8$ ( $n=5 \mu \mathrm{CT}, n=3$ histo $)$
$0.4 \mathrm{mg} / \mathrm{mL}$ vancomycin

intravenous for $3 \mathrm{~d}$ post-operation

$4 \mathrm{mg} / \mathrm{mL}$ vancomycin

intravenous for $3 \mathrm{~d}$ post-operation

control

$20 \mathrm{wt} \%$ vancomycin

20 wt $\%$ vancomycin +

30 wt \% farnesol
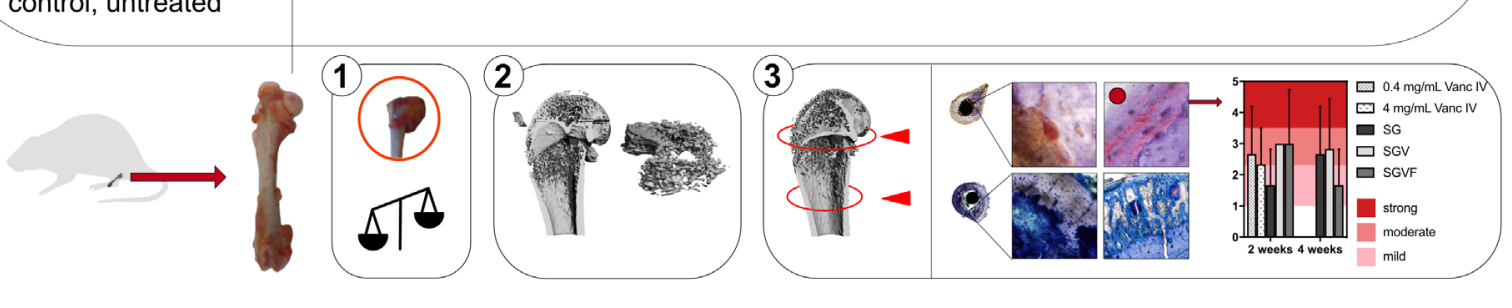

b
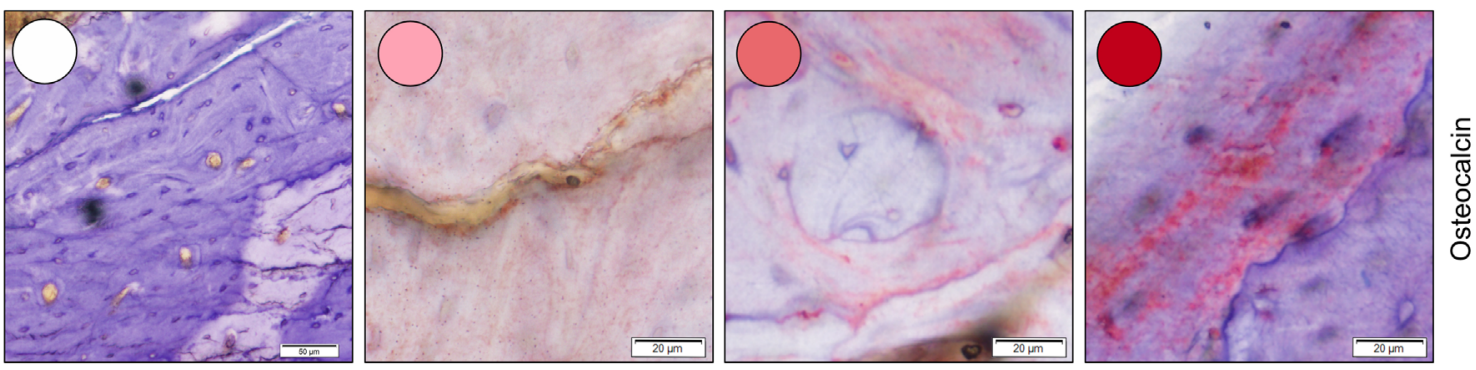

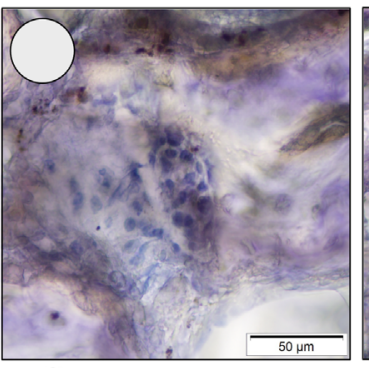

negative control

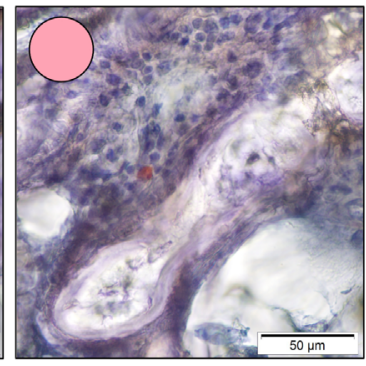

mild

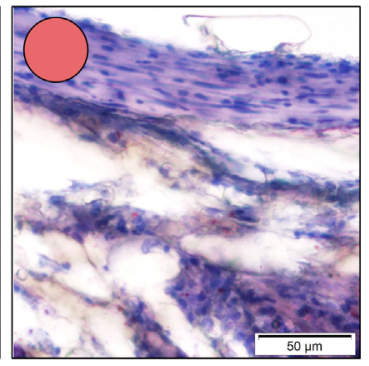

moderate

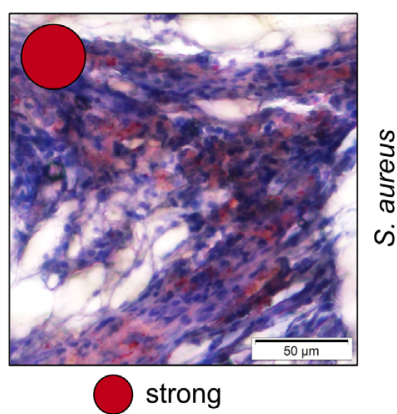

Fig. 1. Study design and immunoscoring. (a) Study design: experimental groups receiving SG-coated intramedullary implants (SG), SG-coated intramedullary implants with vancomycin incorporation (SGV), SG-coated intramedullary implants with combined incorporation of vancomycin and farnesol (SGVF), intramedullary implants with SG coating and intravenous administration of 0.4 or $4 \mathrm{mg} / \mathrm{mL}$ vancomycin intravenously (Vanc IV) for 2 or 4 weeks. (1) Clinical analysis, (2) $\mu \mathrm{CT}$ analysis and (3) histological and immunohistological staining were performed. (b) Immunohistochemical scoring. Upper panel, immunohistochemical staining for OC of bone tissue. Left to right: negative control using $\alpha$-mouse IgG, mild OC score, moderate and strong OC score. Lower panel, immunohistochemical staining for S. aureus (ab20920): mild, moderate and strong scores of S. aureus. 
photographed and used for further analysis. The retrieved femora were analysed for the presence of swelling, deformation or enlargement of the condyles, which are common signs of joint inflammation. The contralateral femur served as internal control. A sham-operation was not performed, since the animal model had been fully developed previously. Guidelines of the Institutional Animal Care and Usage Committee of the University of Pennsylvania for the care and use of laboratory animals were followed (ethics approval: IACUC \#802850).

\section{$\mu \mathrm{CT}$ analysis}

A defined section of the distal one-third of the femora was subjected to $\mu \mathrm{CT}$ analysis utilising a Scanco $\mu \mathrm{CT}$ scanner (Scanco $\mu \mathrm{CT} 40$ ) at a medium resolution of $20 \mu \mathrm{m}$, with energy of $55 \mathrm{kV}$ and $145 \mu \mathrm{A}$. Approximately 500 cross-sectional slices were generated and stacked to facilitate 3D-visualisation, determining bone volume per total volume. For morphometric analysis, the range 500-700 HU was arbitrarily assigned to represent the high-density cortical bone, while the range 225-500 HU represented the low-density endosteal, periosteal and trabecular bone. For qualitative trabecular bone analysis, the additional parameters of trabecular number, spacing and thickness were recorded.

\section{Histological analysis}

Immunohistochemical analysis on undecalcified hard tissue sections was performed as described previously (Knabe et al., 2006), with an optimised embedding resin, which maintained the antigenicity of the bone tissue and provided adequate material properties for sectioning. At retrieval, the femora were fixed using HistoChoice $^{\circledR}$ Tissue Fixative (AMRESCO, Solon, $\mathrm{OH}, \mathrm{USA}$ ) for up to $7 \mathrm{~d}$ at RT. This was followed by dehydration in $5 \%$ polyethylene glycol (Merck) for $7 \mathrm{~d}$ at $-20^{\circ} \mathrm{C}$, in acetone and in benzoin methyl ether at $-4{ }^{\circ} \mathrm{C}$ and xylene at RT, for $1 \mathrm{~d}$ each. For infiltration, freshly destabilised methylmethacrylate, destabilised benzoin methyl ether and polyethyleneglycole 400 (Merck) were used at a ratio of $40: 60: 2$. Subsequently, the specimens were embedded in a resin containing methylmethacrylate and n-butylmethacrylate in a ratio $2: 3$, to which benzoylperoxide $(5 \%)$, polyethyleneglycol $400(5 \%)$ and n,n-dimethylp-toluidine (1\%) (Merck) were added, and cured for $7 \mathrm{~d}$ at $-4{ }^{\circ} \mathrm{C}$. After polymerisation, the blocks were mounted on stubs (Technovit 3040, Kulzer, Hanau, Germany) and glued to acrylic slides (Nr. 404150/GLS, Patho-Service/Walter-Messner GmbH, Oststeinbek, Germany) using an epoxy-resin-based two-component adhesive (UHU, Bühl, Germany). $50 \mu \mathrm{m}$-thick cross-sectional sections were cut (SP1600 microtome, Leica) perpendicular to the long axis of the rat femur and polished. Toluidine blue staining was employed for histological and histomorphometric analysis (Mulisch and Welsch, 2015; Williams, 1941). For further analysis, the sections were deacrylised in toluene (40 $\mathrm{min})$, xylene (40 $\mathrm{min})$ and acetone (10 $\mathrm{min})$ and placed in a humidified chamber at RT. The TRAP staining was carried out as described previously (Kaplow, 1955) and scored as positive, if positively stained osteoclasts were present (positive: score 1) or as negative in the absence of positively stained osteoclasts (negative: score 0). Subsequently, immunohistochemical staining was performed using the DAKO System (S2022, S2003, K4063, K3461, DAKO, Agilent) and primary antibodies specific for $S$. aureus (1:500, ab20920, Abcam), ALP (1 : 4,000, ab95462, Abcam), BSP (1 : 200, LF-84, provided by Larry Fisher), OC (1 : 200, ab13420, Abcam), COL I (1 : 100, ab34710, Abcam) and mouse IgG (1:125,000, PP54 EMD, Millipore) as well as rabbit IgG (1:5,250, PP64 EMD, Millipore) as a negative controlas a negative control (Fig. 5b). One section per femur was stained for each examined marker. Filtered Mayer's haematoxylin (Merck) was used as counterstain; Kaiser's glycerol gelatine (Merck) was used for mounting coverslips. The sections were examined with respect to matrix components, trabecular and cortical bone, osteoid, bone marrow spaces and fibrous matrices by light microscopy. The stained sections were analysed for cellular components such as osteoblasts, osteocytes, osteoclasts and fibroblasts. General criteria (Illgner et al., 2013) of osteomyelitis, such as periosteal bone formation (Fig. 4a, 1), signs of acute osteomyelitis, such as the presence of micrabscesses (Fig. 4a, 4), oedematous medullary canal tissue (Fig. 4a, 5), necrotic bone trabecula and detection of TRAPpositive osteoclasts were evaluated. Criteria for chronic osteomyelitis, such as reactive bone formation (Fig. 4a, 9), focal inflammatory disease bone resorption (Fig. 4a, 3,6), fibrosis of marrow spaces (Fig. 4a, 4) and granulocyte-rich or plasma-cell-rich infiltrate (Fig. 4a, 7,8) were also examined (Fig. 4a). The intensity of the immunohistological staining was categorised as localised/generalised, mild/moderate/ strong and received a corresponding score (Fig. 1b), as previously described (Knabe et al., 2008). The scoring of the $S$. aureus infiltration was performed with respect to density of bacteria in the tissue in an analogous manner (Fig. 1b). Histological sections of the right femur were cut and stained for the various markers in the knee and shaft regions. Each section was examined twice with an interval of at least $3 \mathrm{~d}$ by the same examiner, showing substantial intra-rater reliability.

\section{Statistical analysis}

Intra-rater reliability was determined with weighted $\kappa$-Cohen coefficient (Landis and Koch, 1977), showing substantial agreement for the immunohistological scoring of SA, ALP, BSP, OC and moderate for the scoring of COL I. Statistical analysis included computation of mean values, standard deviations, median, while a Shapirow-Wilk test (Royston, 1995) was applied to check for normal distribution of the values. In case of normal distribution, the parametric analysis of variance two-way ANOVA 
without replication was used, with subsequent Tukey post-hoc test corrected for multiple comparisons. Non-normally distributed values were analysed by the Kruskal-Wallis test and the subsequent Dunn's post-hoc test corrected for multiple comparisons. Significance was assumed achieved for $p<0.05$.

\section{Results}

\section{Clinical results}

The average weight of the rats in all experimental groups was $355 \pm 17 \mathrm{~g}$ at baseline. After 2 weeks, the animals in all experimental groups gained less weight than expected for Sprague-Dawley rats. After 4 weeks, the SGV and SGVF groups displayed a weight comparable to the age-matched standard, while in the SG and Vanc IV groups it remained lower (Fig. 2a). These weight differences observed clinically were not statistically significant.

Clinically, the contralateral femora consistently showed no signs of inflammation, with uniform morphology. In the Vanc IV and SG groups, the treated femoral condyles of the knee showed obvious symptoms of an acute inflammation, being enlarged and displaying periosteal new bone formation, paraosseous abscesses and inflammatory changes of the cartilage. In the $4 \mathrm{mg} / \mathrm{mL}$ and $0.4 \mathrm{mg} / \mathrm{mL}$ Vanc IV groups, these inflammatory signs were strong, while the SG group displayed moderate to strong signs at both time points. In the SGV and SGVF groups, no inflammatory signs at 2 weeks and mild signs at 4 weeks were noted (Fig. 2b).

\section{$\mu \mathrm{CT}$ analysis}

The $\mu \mathrm{CT}$ analysis of the complete bone structure of both femora in the 3D reconstruction of sagittal sections showed in the SG and $4 \mathrm{mg} / \mathrm{mL}$ Vanc IV groups after 2 weeks signs of destruction and discontinuity of the osseous and cartilaginous tissue in the joint area with dilated lumina, which are indicative of persistent infection and inflammation. In the SGV group, the osseous microanatomical architecture was well preserved, while the SGVF group displayed an almost fully preserved osseous microarchitecture (Fig. 3a).

The analysis of BV/TV of the right-treated femora yielded statistically significant differences between the $4 \mathrm{mg} / \mathrm{mL}$ Vanc IV and SGV ( $p=0.0463)$ groups and the $4 \mathrm{mg} / \mathrm{mL}$ Vanc IV and SGVF $(p=0.0106)$ groups at 2 weeks. After 4 weeks, a similar result was obtained with destruction of bone and cartilage being noted in the SG and $4 \mathrm{mg} / \mathrm{mL}$ Vanc IV groups when compared to a very well-preserved microarchitecture of the osseous and cartilage tissues in the joint area in the SGV and SGVF groups. The BV/TV in the right-treated femora was significantly higher in the SGV ( $p=0.0002)$ and SGVF groups $(p=0.0017)$ when compared to the $4 \mathrm{mg} / \mathrm{mL}$ Vanc IV group (Fig. $3 \mathrm{~b}$ ). Furthermore, statistically significantly higher BV/TV values for the left-untreated femora were observed in the SG $(p=0.0348)$ and SGV $(p=0.0006)$ groups when compared to the $4 \mathrm{mg} / \mathrm{mL}$ Vanc IV group.

The analysis of the cancellous bone microanatomy showed differences in trabecular thickness, number and spacing, with an inverse trend of number to distance and an obviously more grossly meshed structure in the 3D reconstruction for the $4 \mathrm{mg} / \mathrm{mL}$ Vanc IV group (Fig. 3c). In detail, in the SGV and SGVF groups a trend towards increase in trabecular thickness was noted from 2 to 4 weeks, while in the SG and $4 \mathrm{mg} / \mathrm{mL}$ Vanc IV groups a trend towards decrease of the trabecular thickness was observed from 2 to 4 weeks. These differences were statistically significant ( $p=0.0183)$, with the post-hoc test, however, not yielding any further differentiation (Fig. 3d). Trabecular spacing significantly increased in the $4 \mathrm{mg} / \mathrm{mL}$ Vanc IV group when compared to the SG, SGV and SGVF groups ( $p=0.0001)$. At 2 weeks, in the right-treated femora of the $4 \mathrm{mg} / \mathrm{mL}$ Vanc IV group, significantly larger trabecular spacing was noted as compared to the SGV ( $p=0.0371)$ or SGVF ( $p=0.0013)$ groups. Also at 4 weeks, the trabecular spacing was larger in the right femur of the $4 \mathrm{mg} / \mathrm{mL}$ Vanc IV group when compared to the SGV $(p=0.0002)$ and SGVF ( $p=0.0067)$ groups, respectively (Fig. 3e). The same was true when comparing the left femur of the $4 \mathrm{mg} / \mathrm{mL}$ Vanc IV group to the SG $(p=0.0480)$, SGV $(p=0.0150)$ and SGVF $(p=0.0128)$ groups at 4 weeks. As a result, the trabecular number in the right-treated femora was significantly different $(p=0.0001)$, with larger numbers being present at 2 weeks in the SGVF group when compared to the left $(p=0.0237)$ and right femora $(p=0.0181)$ of the $4 \mathrm{mg} / \mathrm{mL}$ Vanc IV group. Also, the right femora of the SGV group exhibited statistically significant larger trabecular numbers when compared to the $4 \mathrm{mg} / \mathrm{mL}$ Vanc IV group ( $p=0.0020)$. At 4 weeks, the findings were similar in that the left femora of the SG $(p=0.0433)$, SGV $(p=0.0005)$ and SGVF $(p=0.0020)$ groups as well as the right femora of the SGV $(p=0.0007)$ group displayed significantly larger trabecular numbers than the femora of the $4 \mathrm{mg} / \mathrm{mL}$ Vanc IV group (Fig. $3 \mathbf{f})$. The results of the $\mu \mathrm{CT}$ analysis showed the bestpreserved osseous microanatomy in the SGV group, followed by the SGVF group, with a trend towards increase in trabecular thickness from 2 to 4 weeks in the SGV and SGVF groups. In contrast, in the SG and the Vanc IV groups a decrease in trabecular thickness and marked osteomyelitic changes were present.

\section{Histological results}

Histological signs that are regarded as criteria for the diagnosis of an acute osteomyelitis entail periosteal bone formation, microabscesses, oedematous medullary canal tissue, necrotic bone trabeculae and presence of TRAP-positive osteoclast; criteria for the diagnosis of a chronic osteomyelitis include reactive bone formation, focal inflammatory bone resorption, fibrosis of marrow spaces and granulocyte-rich or plasma-cell-rich infiltrate (Tiemann et al., 2014). In the SG, SGVF and $4 \mathrm{mg} / \mathrm{mL}$ Vanc IV groups, 
periosteal bone formation was present in two out of three animals both at 2 and 4 weeks, and in all rats in the $0.4 \mathrm{mg} / \mathrm{mL}$ Vanc IV group. In the SGV group, periosteal bone formation occurred only in one animal at 2 weeks. At 2 weeks, the largest amount of necrotic bone, which is one of the key criteria for the presence of an acute osteomyelitis, was observed in the femora of the $0.4 \mathrm{mg} / \mathrm{mL}$ Vanc IV group, followed by the $4 \mathrm{mg} / \mathrm{mL}$ Vanc IV and SG groups. At 2 weeks, massive bone resorption was observed in the 0.4 and $4 \mathrm{mg} / \mathrm{mL}$ Vanc IV groups, while at 4 weeks more localised inflammation with bone destruction, which is regarded as a diagnostic criterion for chronic osteomyelitis (Tiemann et al., 2014), was noted. The medullary canals displayed oedematous infiltrate with diffusely distributed lymphocytes and granulocytes, so-called microprocesses, when an acute inflammatory stage was present, or granulocyte-rich and plasma-cell-rich infiltrates in the case of chronic inflammation. The analysis of the TRAP staining detected osteoclasts in the diaphysis of two thirds of the femora in the SG, SGV and SGVF groups at both time points and in one third of the femora in the $4 \mathrm{mg} / \mathrm{mL}$ Vanc IV group (Fig. $4 \mathrm{~b}$ ). In the epiphysis, minor amounts of osteoclasts were noted in one out of three animals from all groups at 2
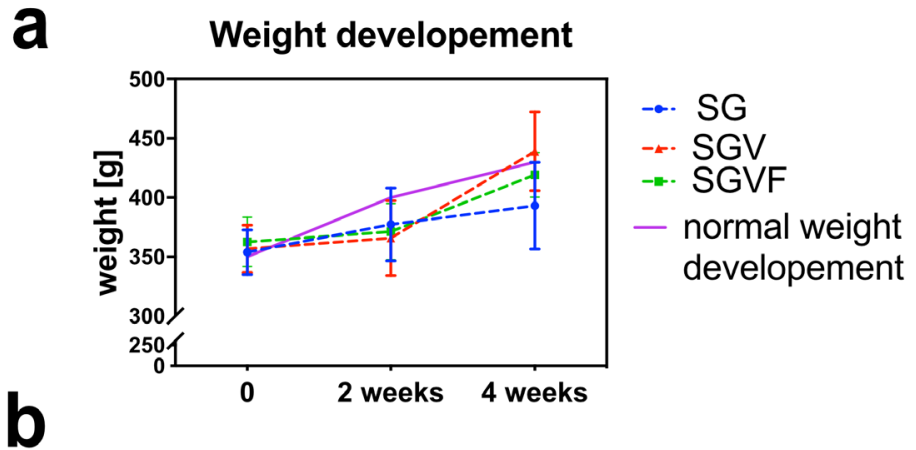
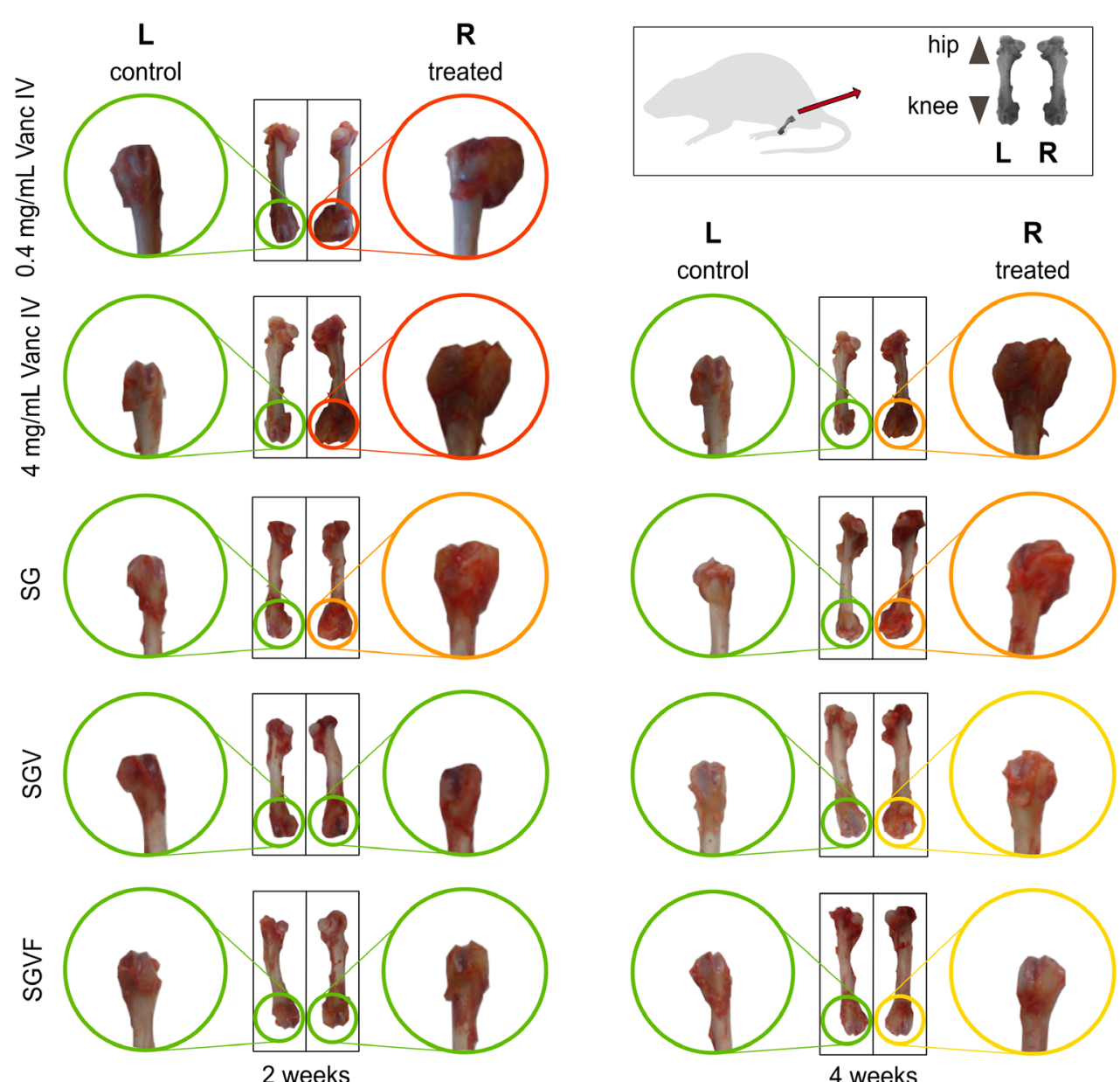

Fig. 2. Clinical results. (a) Line graph demonstrating the weight development of the rats in the various experimental groups. All values are mean weight $(\mathrm{g}) \pm \mathrm{SD}$ (dots). The line graph depicts the weight at the beginning of the experiment (0) and at femur retrieval (at 2 and 4 weeks) for SG, SGV and SGVF groups as compared to the normal weight development provided by Charles River (pink line). (b) Clinical signs: representative photographs of untreated left and treated right femora retrieved at 2 or 4 weeks after inoculation with $10^{3} \mathrm{CFU}$ MRSA, implant placement with or without intravenous vancomycin administration. SG, SGV, SGVF and intravenous control groups: 0.4 and $4 \mathrm{mg} / \mathrm{mL}$ Vanc IV. 
and 4 weeks, except for the SGV group at 2 weeks, in which no osteoclasts were observed. A physiological bone marrow structure with haematopoiesis was absent in all animals. The femora of the SGV group displayed new bone formation within the medullary canal at 2 weeks. The same was true for one animal at 4 weeks. Furthermore, the formation of a thin bony lamella around the pin was noted in all animals.
Taken together, the femora of the 0.4 and $4 \mathrm{mg} / \mathrm{mL}$ Vanc IV groups displayed the strongest extent of inflammatory signs, followed by the femora of the SG group, with only mild signs being present in the SGV and SGVF groups, which is in good correspondence with the clinical findings. At the same time there was some variation noted with respect to the extent of inflammatory signs within the various test groups. a

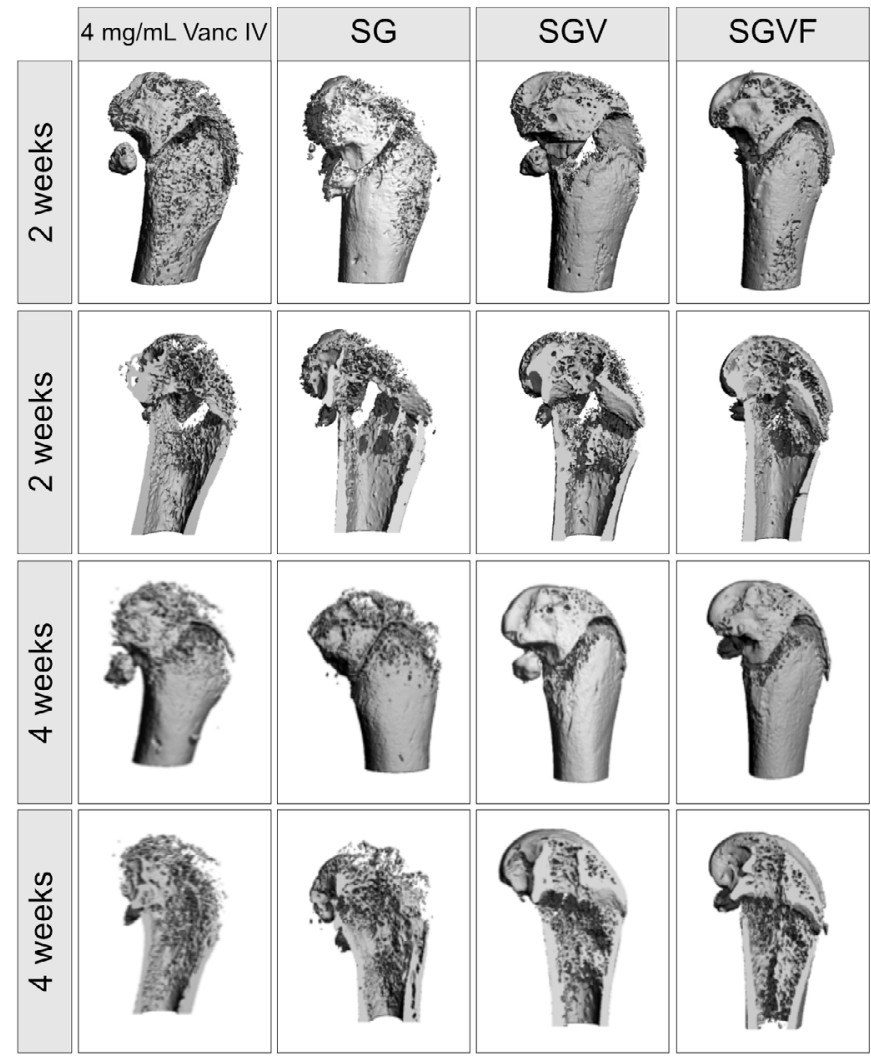

C

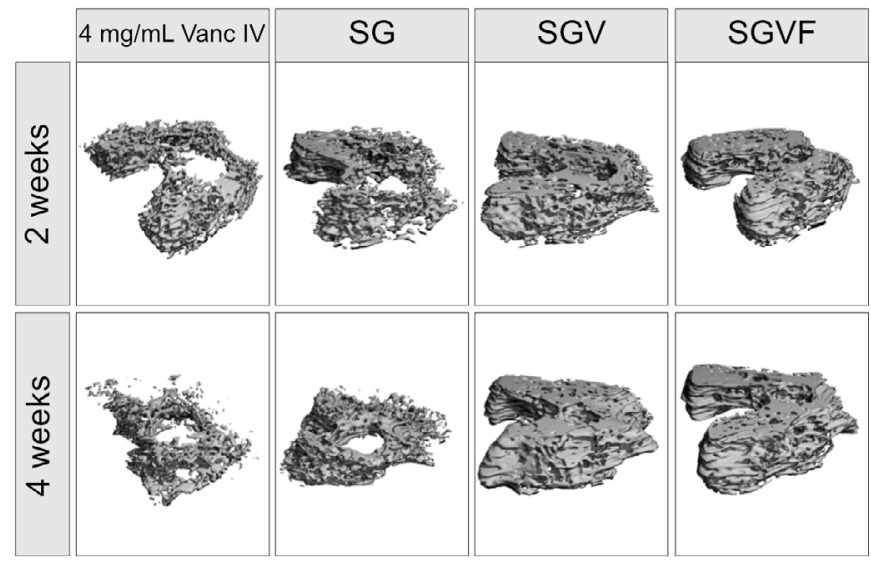

b Bone volume / total volume (BV/TV)
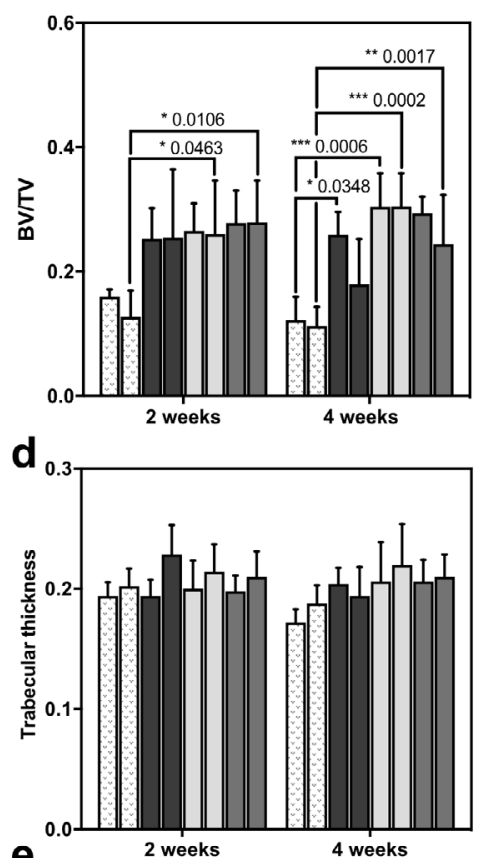

$4 \mathrm{mg} / \mathrm{mL}$ Vanc IV

$\square$ SG

$\square$ SGV

$\square$ SGVF

two-way ANOVA:

$p$-value surface $^{=}=0.0183$

$p$-Wert time $=0.2792$

$p$-Wert interaction $=0.1570$

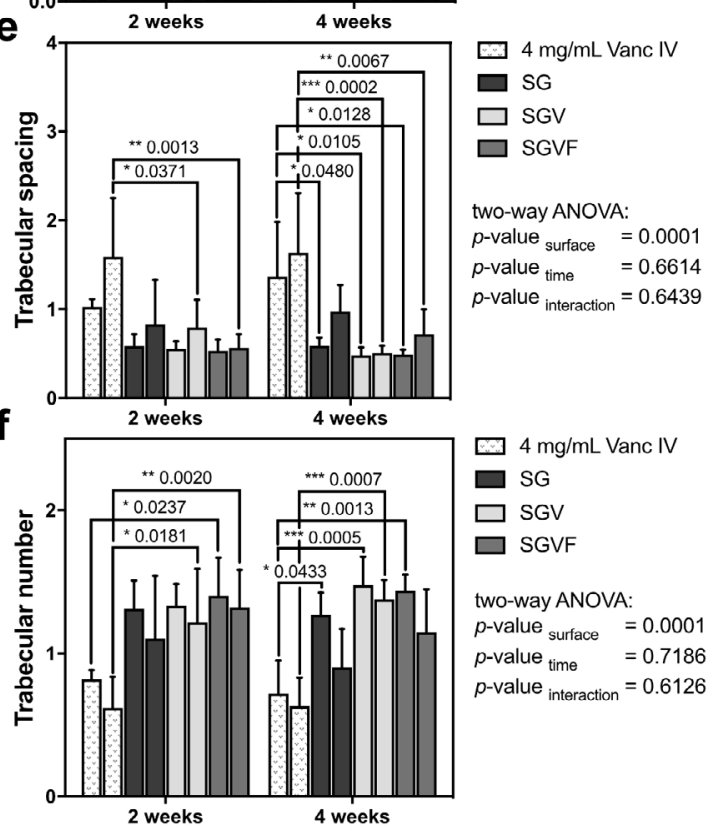

Fig. 3. $\mu \mathrm{CT}$ analysis. (a) Bone volume analysis: 3D-reconstruction of the complete bone and sagittal sections at of the right femur of the SG, SGV, SGVF and $4 \mathrm{mg} / \mathrm{mL}$ Vanc IV groups at 2 or 4 weeks. (b) Bone volume analysis: statistical analysis of TRI-optimised values of BV/TV; left bar represents left femora, right bar represents right femora; $p$-values below and significant differences indicated above the bars (two-way ANOVA, Tukey post-hoc). (c) Trabecular analysis: 3D reconstruction of trabecular bone (225-500 HU) in cross-sections of the right femur of the SG, SGV, SGVF and $4 \mathrm{mg} / \mathrm{mL}$ Vanc IV groups at 2 or 4 weeks. (d-f) Trabecular analysis: statistical analysis of TRI-optimised values of trabecular number, spacing and thickness; left bar represents left femora, right bar represents right femora; $p$-values below and significant differences indicated above the bars (two-way ANOVA, Tukey post-hoc). 
a

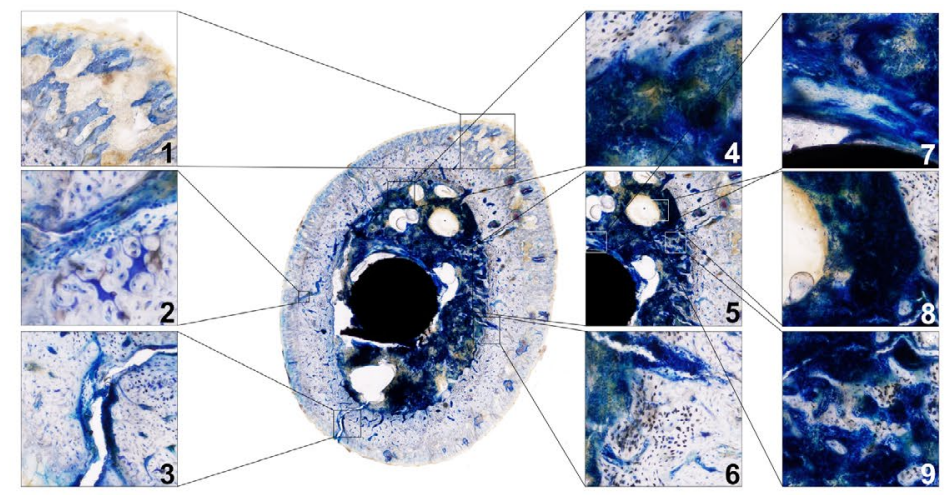

b Osteoclasts in epiphysis

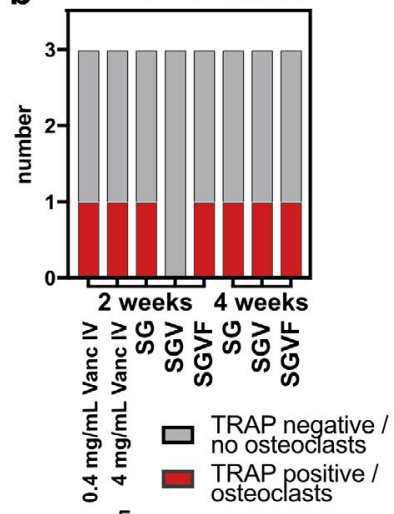

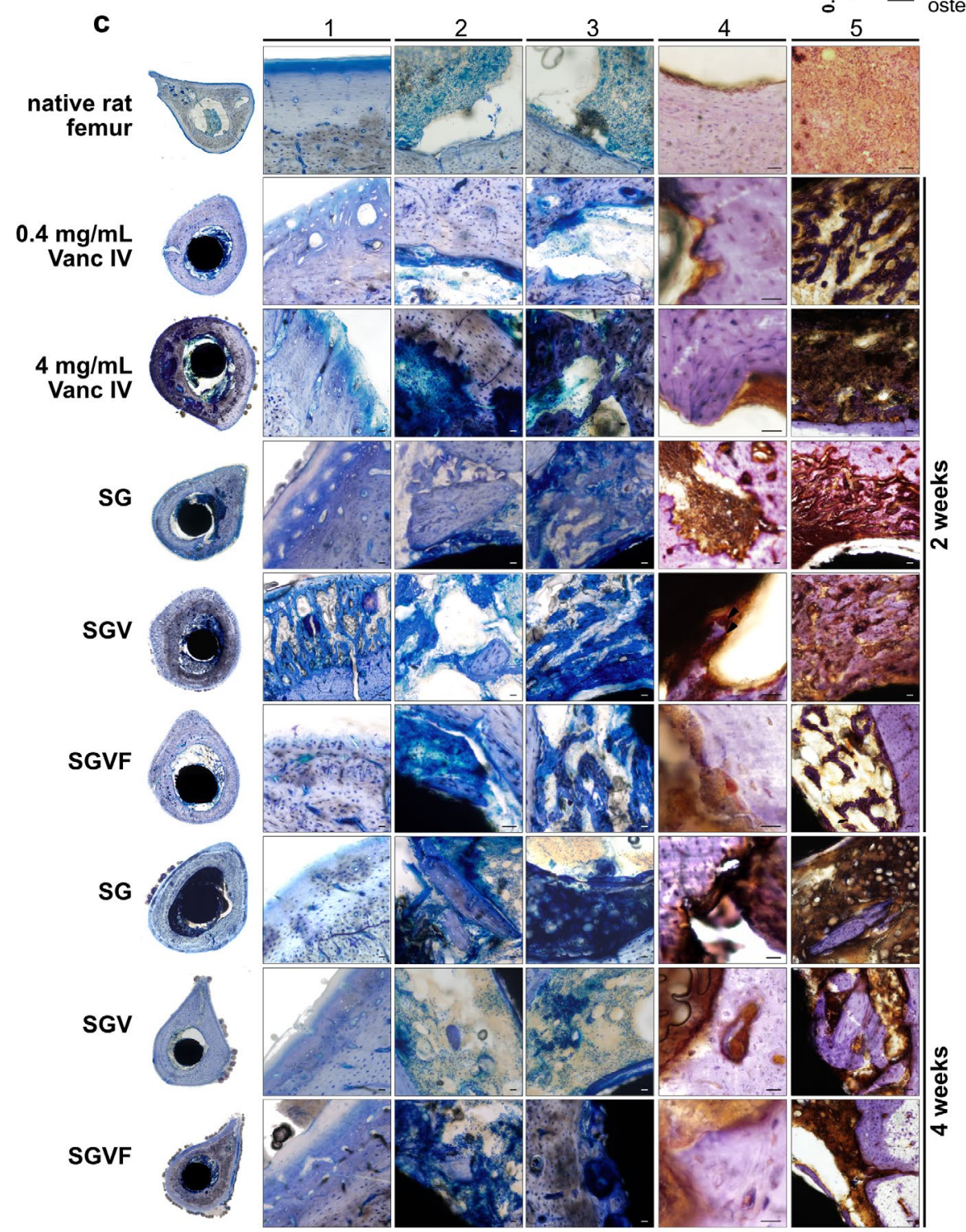

Fig. 4. Histological findings of the various experimental groups. (a) Histomicrographs of toluidine-bluestained histological section demonstrating signs of osteomyelitis. (2) Bone formation. (1) General criteria for osteomyelitis: periosteal bone formation. Criteria for acute osteomyelitis: (4) microabscesses, (5) oedematous medullary canal tissue. Criteria for chronic osteomyelitis: $(3,6)$ focal inflammatory disease bone resorption, $(7,8)$ granulocyte-rich or plasma-cell-rich infiltrate, $(9)$ reactive bone formation. (b) Results of TRAP staining: histomicrograph showing a TRAP-positive osteoclast. Histogram delineating number of animals per experimental group in which TRAP-positive osteoclasts were observed. (c) Representative histomicrographs of toluidine-blue-stained histological sections demonstrating periostal bone apposition (1), presence of sequesters/necrotic bone material (2), obstruction of bone marrow of the right femur (3) with the pin in situ. Representative histomicrographs of immunohistochemically stained sections showing inflammatory changes in the cortical bone (4) and bone marrow of the right femur (5) with the pin in situ. Microscopic anatomy of a representative native rat femur is shown as reference. Scale bars: $20 \mu \mathrm{m}$. 


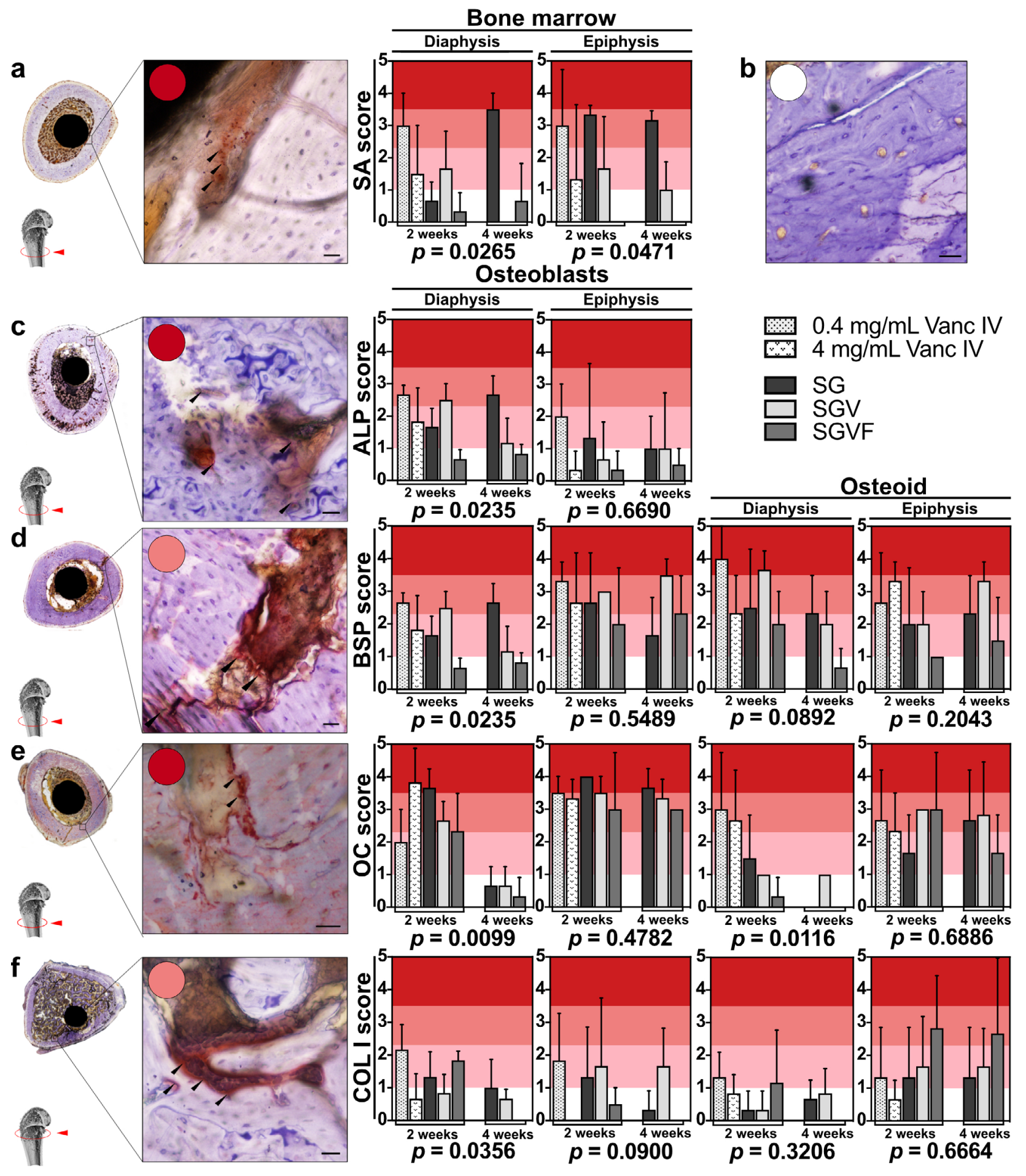

Fig. 5. Results of the immunohistochemical staining and immunoscoring. Representative histomicrographs with score (mild, moderate, strong: colour scheme as explained in Fig. 1) indicated in red circles, of resinembedded-sawed section stained immunohistochemically. Scale bars: $20 \mu \mathrm{m}$. Histograms depicting the immunoscoring results for each respective marker with score $0-5$ (y-axis, rage of mild, moderate and strong represented by the corresponding colours in the background) in the right femoral epiphysis and diaphysis at 2 and 4 weeks (x-axis) for $0.4 \mathrm{mg} / \mathrm{mL}$ Vanc IV, $4 \mathrm{mg} / \mathrm{mL}$ Vanc IV, SG, SGV, and SGVF with $p$-values. (a) $S$. aureus (SA), with strong $S$. aureus infiltration in the bone marrow. (b) Negative control. (c) ALP, with strong expression in osteoblasts (arrowheads). (d) BSP, with moderate BSP expression in osteoblasts (arrowheads). (e) OC, with strong OC expression in osteoblasts (arrowheads) and moderate staining in the mineralised bone matrix. (f) COL I, with moderate COL I expression in osteoblasts. 


\section{Immunohistological results}

Tissue infiltration with MRSA, which is considered direct evidence of a MRSA infection, was noted in the medullary canal near bone sequesters or the pin, in the area of bone sequesters as well as in niches in the medullary canal and epiphysis. In the bone marrow, a significantly higher infiltration of MRSA was observed in the diaphysis $(p=0.0265)$ and epiphysis ( $p=0.0471)$ of the SG and 0.4 and $4 \mathrm{mg} / \mathrm{mL}$ Vanc IV groups (Fig. 5a), while there was complete suppression of MRSA infiltration in the epiphysis of the SGVF group.

Positive ALP expression was mainly observed in osteoblasts, with significant differences being noted in the area of the femoral diaphysis, where osteoblasts expressed significantly higher ALP levels in the SG as compared to the SGVF group at 4 weeks. Osteoblasts in the SGVF group consistently displayed low ALP expression levels both at 2 and 4 weeks $(p=0.0235)$ (Fig. 5c). With respect to the expression of BSP, an osteogenic marker characteristic of the terminally differentiated osteoblasts and extracellular matrix mineralisation, in the SGVF group lower expression levels were observed in the osteoblasts in the diaphyseal region at both time points when compared to the other experimental groups. However, these differences were only statistically significant when comparing the SGVF and SG groups $(p=0.0235)$ at 4 weeks. These findings were similar to those for ALP (Fig. 5d). The results of the immunohistochemical staining for OC showed higher expression levels in osteoblasts $(p=0.0099)$ and osteoid $(p=0.0116)$ in the diaphyseal region at 2 weeks vs. 4 weeks for the Vanc IV, SG and SGVF groups, with expression levels being the lowest for the SGVF group (Fig. 5e). The Kruskal-Wallis test rendered statistically significant differences for COL I expression levels in osteoblasts $(p=0.0356)$ of the diaphysis (Fig. 5e), with expression levels in the SGVF group being lower at 4 vs. 2 weeks and lower in the SGVF group at 4 weeks as compared to the SG and SGV groups. The results of the osteogenic marker expression revealed more bone remodelling activity in the Vanc IV and SG groups when compared to the SGV and SGVF treatment groups, in which there was a decrease in remodelling activity between 2 and 4 weeks. The lowest remodelling activity was noted in the SGVF group, which was accompanied by the highest degree of suppression of MRSA tissue infiltration.

\section{Discussion}

Osteomyelitis resulting from orthopaedic SSIs poses a major therapeutic challenge due to the presence of the osteosynthesis materials in the infected area (Lew and Waldvogel, 2004; Tiemann et al., 2014; Tiemann, 2017; Walter et al., 2012) and the associated biofilm formation (Gristina and Costerton, 1985; Gristina et al., 1985; Sheehan et al., 2004), which enables bacteria to efficiently evade the host immune response while simultaneously shielding them from the antibiotic (Thammavongsa et al., 2015). The consequences for patients affected by this dire surgical disease are major, as the therapeutic approach entails revision surgery with removal of all infected hard and soft tissue (Ger, 1977; Mathes et al., 1982; Parsons and Strauss, 2004; Schwameis et al., 1996; Tiemann, 2017; Waldvogel et al., 1970), often including removal of the osteosynthesis material (Schierholz et al., 2004; Schnettler and Steinau, 2004), resulting in extensive hard and soft tissue defects. Reconstruction of these major hard and soft tissue defects often requires numerous additional surgeries involving the combined efforts of bone reconstructive and plastic surgery and long rehabilitation periods, during which maintaining optimal function in the patient's extremity can represent a major challenge (Parsons and Strauss, 2004; Tiemann, 2017).

Orthopaedic SSIs are frequently caused by $S$. aureus, with an increasing incidence of infections in the presence of resistant strains such as MRSA (Kavanagh et al., 2017), which creates the need for appropriate antibiotic therapy. Clinically, the most frequently applied treatment is systemic antibiotic with intravenously administered vancomycin (Fraimow, 2009; Tiemann, 2017). The shortcomings associated with intravenous administration of antibiotics outlined above have led to a great demand for novel therapeutic concepts, which entail effective modes of local administration in addition to the development of new antimicrobial agents or combination therapies.

At present, the clinically available treatment options for local administration of antibiotics to osseous sites include antibiotic-loaded bone cement and PMMA beads that, however, require secondary surgery for their removal (Adams et al., 1992; Fraimow, 2009). Osteosynthesis materials with antibiotic-loaded polymer coatings such as the PROtect ${ }^{\mathrm{TM}}$ coating have also become available (Fuchs et al., 2011). But with gentamycin incorporation and resistance of $17 \%$ of MRSA to gentamycin, it is unclear whether these coatings can prevent MRSA infections in all patients (Centers for Disease Control and Prevention, 2004; Robert-Koch-Institut, 2015; Witte et al., 2001).

When pursuing the concept of local drug administration and combination therapy, the development of a SG coating with controlled dualdrug delivery and combination of vancomycin, i.e. an established antibiotic for MRSA infections, with the antimicrobial agent farnesol constitutes a promising approach for inhibiting biofilm formation in vivo on titanium-alloy-based osteosynthesis materials. An advantageous property of the SG film is that the antibiotic is fully released at an approximately constant release rate in contrast to the release from PMMA, which is a burst release in the first few hours 
followed by a trickling out and release of ineffective concentrations, which can elicit development of resistance in the surviving bacteria (Anagnostakos et al., 2009; Qu et al., 2015a; Radin and Ducheyne, 2007). Furthermore, the SG coatings used in the present study display excellent mechanical properties protecting them from delamination during the surgical implantation procedure. The crack onset strain is $5 \%$, the crack saturation strain $16 \%$, the critical cracking stress $3.05 \mathrm{GPa}$, the interfacial shear strength $153.37 \mathrm{MPa}$, the film fracture energy $112.43 \mathrm{~J} / \mathrm{m}^{2}$, the interfacial fracture energy $156.21 \mathrm{~J} /$ $\mathrm{m}^{2}$. The release properties of these coatings have been described in detail previously. The initial release concentration for vancomycin is $31.4 \mu \mathrm{g} / \mathrm{mL}$, with a farnesol concentration of $34 \mu \mathrm{g} / \mathrm{mL}$ (Bhattacharyya et al., 2014; Qu et al. 2014).

\section{Animal model}

The present study was designed as a feasibility study examining the efficacy of dual local delivery of vancomycin and farnesol from a SG coating on titanium pins. Therefore, it was performed utilising a previously described small animal, rat osteomyelitis model (Adams et al., 2009; Antoci et al., 2007; Beckmann et al., 2007; Lucke et al., 2003a; Lucke et al., 2003b; Norden, 1988). Since rats are less sensitive to bacterial challenge and pain and form more bone than humans, translation to the clinic requires positive results obtained in the rodent model to be confirmed in a large animal, sheep model $(\mathrm{Qu}$ et al., 2014). When translating a novel technology and medical device to the clinic, in vitro studies are typically followed by in vivo studies using small animal models for proof-of-concept and selection of the most promising implant or device modification. In vivo studies, utilising a clinically relevant large animal in combination with a smaller number of experimental conditions or implant modifications constitute the next tier of scientifically relevant studies for achieving translation to the clinical arena. In this context, there are several differences with respect to bone biology and regeneration between rats and humans. These differences regard bone architecture, rate of bone formation, cortices (consisting of predominantly primary bone in rats), bone-healing capacity (Wancket, 2015) and immune responses (stronger in rats) (Reizner et al., 2014). In contrast, bone formation in sheep is more similar to that in humans (Wancket, 2015). As such, an appropriate sheep infection model was developed in parallel to the rat study to confirm the present findings. Other authors have established suitable rabbit osteomyelitis models (Arens et al., 2015; Helbig et al., 2014). In this context, it must be mentioned that bone biology and (micro)architecture of long bones in rabbits have slightly more similarities to humans as compared to rats (Wancket, 2015). However, since the present study involved transitioning from a rodent model to a sheep model (McGovern et al., 2018) and rats are easier to house and handle as well as being less expensive than rabbits, a previously developed rat osteomyelitis model (Adams et al., 2009) was chosen.

By direct administration of the inoculum $\left(10^{3} \mathrm{CFU}\right.$ MRSA) into the medullary canal, an infection was induced, which spread in a centrifugal manner from the medullary canal and bone marrow to the cancellous bone and periosteum (Rissing, 1990; Schmidt et al., 2014), reliably leading to a persistent infection and the development of an osteomyelitis (Adams et al., 2009; Antoci et al., 2008; Lucke et al., 2003a; Lucke et al., 2003b; Schmidt et al., 2014). In addition, the implantation of the intramedullary titanium alloy Ti-6Al-4V rod favoured biofilm formation and persistence of the infection (Gristina and Costerton, 1985; Gristina et al., 1985; Sheehan et al., 2004). It has been speculated whether the mere presence of an intramedullary rod, i.e. a foreign material, may promote inflammation. However, for SG-coated implants only minimal signs of inflammation are elicited (Adams et al., 2009; Muhonen et al., 2009; Radin et al., 2005; Radin et al., 2002) and osseointegration is facilitated even in the presence of a bacterial challenge (Qu et al., 2015b).

Parallel to the rat study described, which was a first feasibility study with a limited number of animals, a sheep model was developed for studying the efficacy of intramedullary nails solely releasing vancomycin as the next step in translation to the clinic, subsequent to the rat study described by Adams et al. (2009). The sheep study included more time points and a larger number of animals with larger implants, thereby facilitating using different portions of the intramedullary nails for different types of analyses, including biofilm formation, by scanning electron microscopy and confocal laser scanning microscopy, bacterial cultures and histology and immunohistochemistry. Since, in the present study, the intramedullary pins were left in place for the histological analysis, with the goal of examining the tissue response at the SG-tissue interface, additional animals would have been required for the bacterial cultures and biofilm formation analyses. Immunohistochemical analysis of tissue infiltration by $S$. aureus was performed on the same implant sites as used for the histological analyses. However, given the small study size and having successfully performed biofilm formation and bacterial culture analysis in a previous rat study with SG-coated pins (Adams et al., 2009), these analyses were not performed in the present study. In the present study, statistical analysis of bacteriological results was not included in order to avoid the need for multivariate analysis, which would have been difficult with the given sample size. However, these analyses are included in the design of the sheep study. Such a study will follow as a next step for translation to the clinic. In this large animal study, analysis of biofilm formation on the SG-coated intramedullary rods, as well as characterisation of vancomycin and farnesol 
serum levels will constitute an integral part of the programme (Qu et al., 2014).

\section{Clinical results}

Macroscopically enlarged femoral condyles of the knee and periosteal new bone formation at femur retrieval (Fig. 2b), which are signs of inflammation (Braunschweig et al., 2011; Lew and Waldvogel, 2004; Mader and Calhoun, 1996; Tiemann, 2017; Waldvogel et al., 1970), were observed in the knee region and less pronounced in the shaft region. This may be related to the surgical model chosen, which involved accessing the medullary canal for implantation of the intramedullary rod and administration of the inoculum from the knee. The less pronounced inflammatory signs observed in the SGV group were in accordance with previous radiological findings (Adams et al., 2009). Moreover, the pronounced inflammatory changes observed at the macroscopical level, both in the SG and the Vanc IV groups in contrast to their absence at 2 weeks and observation of slight changes at 4 weeks in the SGV and SGVF groups, corroborated the antibacterial efficacy of these two coatings. In studies employing a similar rat model and using implants with a gentamycincontaining coating to prevent osteomyelitis, the mere weight of the animals was not considered to be a strong parameter for distinguishing between the presence and absence of an infection (Fölsch et al., 2016; Lucke et al., 2003b; Lucke et al., 2005).

\section{$\mu \mathrm{CT}$ analysis}

$\mu \mathrm{CT}$ analysis is a highly sensitive tool, which facilitates precise 3D visualisation and analysis of the osseous microarchitecture, after removal of the pin to reduce metallic artefacts (Sarve et al., 2011), including triangulation of surfaces (Lorensen and Cline, 1987). As a result, $\mu \mathrm{CT}$ analysis is superior with respect to determining differences between the experimental groups when compared to weight measurement as well as analyses performed on conventional 2D X-rays (Bouxsein et al., 2010; Engelke et al., 1999; Freeman et al., 2009). Trabecular and cortical bone components were identified based on their density (Adams et al., 2009) and subsequently analysed with respect to volume (BV/TV) and quantitative analysis of trabecular microanatomy in terms of number, thickness and spacing (Bouxsein et al., 2010; Yeom et al., 2008).

In the SG and Vanc IV groups, the 3D reconstruction showed enlarged condyles with a more loosely meshed osseous microarchitecture and cortical disruptions and osteolysis (Fig. 3a), a significantly lower total (Fig. 3b) and cancellous bone volume (Fig. 3c) as well as a considerable decrease in quality of the internal trabecular microarchitecture with respect to thickness, number and spacing (Fig. 3df), which is indicative of a fully developed MRSAinfection-associated tissue response (Widaa et al., 2012). In comparison, in the SGV group and to a slightly lesser degree in the SGVF group, a well- maintained osseous microanatomy was noted, with the largest percentage of total bone volume and a pronounced trabecular network, so that the SGV group yielded the best $\mu \mathrm{CT}$ results in the present experimental in vivo setup. In this, it was closely followed by the SGVF group, for which $\mu \mathrm{CT}$ analysis rendered significantly better results than those noted for the SG and the Vanc IV groups, which showed the most pronounced destruction of the osseous microarchitecture. Moreover, the results of the $\mu \mathrm{CT}$ analysis showed a tendency towards an increase in trabecular thickness between 2 and 4 weeks in the SGV and SGVF groups, while in the SG and $4 \mathrm{mg} / \mathrm{mL}$ Vanc IV groups a decrease in trabecular thickness was observed from 2 to 4 weeks, with these differences being statistically significant. In addition, the results of the immunohistochemical analysis demonstrated that this was accompanied by a lower remodelling activity, which further decreased between 2 and 4 weeks (being the lowest for the SGVF group), and a significant lower infiltration of the bone marrow with MRSA. Taken together, these findings demonstrated that both the SGV and SGVF also inhibited MRSA-infection at 4 weeks. When taking into consideration the radiological criteria for osteomyelitis (Braunschweig et al., 2011) and the conclusions made by authors of similar studies (Lucke et al., 2003a; Lucke et al., 2003b; Lucke et al., 2005; Mecikoglu et al., 2006), the findings of the microarchitecture (as revealed by $\mu \mathrm{CT}$ ) and of the osteogenic marker expression (as revealed by immunohistochemical analysis) in the SGV and SGVF groups were indicative of an inhibitory effect on the MRSA-induced osteomyelitic remodelling processes in vivo. This was in agreement with previous $\mu \mathrm{CT}$ results for the SGV group (Adams et al., 2009).

\section{Histological analysis}

Histological evaluation (Fig. 4) was performed on undecalcified resin-embedded sections (Knabe et al., 2006) employing the same criteria used for evaluating osteomyelitis in histological sections prepared from human tissues removed during revision surgery (Braunschweig et al., 2011; Illgner et al., 2013; Tiemann, 2017). These criteria were furthermore applied by other authors who conducted similar studies also utilising rat models (Beckmann et al., 2007; Lucke et al., 2003a; Lucke et al., 2005; Mecikoglu et al., 2006). In the present study, histological sections were prepared perpendicularly to the long axis of the femur, in order to compare the histological images with the cross-sectional planes chosen for the $\mu \mathrm{CT}$ analysis, while other authors examined longitudinal histological sections prepared parallel to the long axis of the rat femur (Lucke et al., 2003a; Lucke et al., 2003b; Lucke et al., 2005). Since hard-tissue histology, including cutting of resin-embedded sawed sections, was performed, it was only possible to cut a limited number of sections from the small bone blocks due the small size of the rat femur. As a result, it was only possible to stain one section per marker 
immunohistochemically. Histological analysis revealed findings that are regarded as criteria for the diagnosis of an acute or chronic osteomyelitis, such as microabscesses, oedematous medullary tissue and necrotic bony trabeculae (Herrmann et al., 2005; Illgner et al., 2013; Tiemann et al., 2014). For the diagnosis of an acute or chronic osteomyelitis to be made, a sufficient number or these signs, with a sufficient degree or severity, needs to be present (Tiemann et al., 2014). A modification of the haematoxylin-eosin staining protocol, involving optimisation of the epoxy adhesive, might have facilitated a better distinction between inflammatory and bone-marrow-related cells in the present relatively thick $(\sim 20 \mu \mathrm{m})$ hardtissue sawed resin sections.

Periosteal bone formation, which is an important criterion for the diagnosis of bone infection and osteomyelitis, was most pronounced in the Vanc IV and SG groups, while the SGVF and SGV groups exhibited very low periosteal bone formation with the least degree being present in the SGV group. The findings in the SGV group agreed with those of a previous study (Adams et al., 2009) in which low periosteal bone formation was demonstrated when compared to controls. A high degree of inflammatory osteolysis was observed in the Vanc IV groups, which was considerably higher than that noted in the SG group. The detection of osteoclasts by TRAP staining (Minkin, 1982) revealed a decrease in osteoclasts in all groups starting from about 2 weeks. In cases in which sequestering trabeculae are visible histologically, the presence of osteoclasts is considered as a supporting histopathological criterion for the diagnosis of acute bacteria-sequestering osteomyelitis (Herrmann et al., 2005; Illgner et al., 2013; Tiemann et al., 2014). Then, decrease in osteoclasts over time may suggest a temporal transition from an acute bacteriasequestering osteomyelitis to a chronic infection (Lew and Waldvogel, 2004; Schmidt et al., 2014), which has been observed between 4 and 6 weeks (Lucke et al., 2003b; Rissing, 1990; Spagnolo et al., 1993). These authors used a similar rat model to that utilised in the present study. False positive results for the TRAP staining caused by endogenous peroxidase activity in haemoglobin, myoglobin, neutrophils and eosinophilic granulocytes as well as monocytes (Escribano et al., 1987; Nishimura et al., 2016) were excluded in the present study, since positively stained osteoclasts were identified on morphological grounds. The finding that a physiological bone marrow structure with haematopoiesis was missing in the medullary canals in all animals may be related to the fact that lack of haematopoietic tissue in the medullary canal may also have been at least partially related to the implantation of the intramedullary pin in the SG, SGV and SGVF groups.

Taken together, the strongest extent of inflammatory signs was observed in the 0.4 and $4 \mathrm{mg} /$ $\mathrm{mL}$ Vanc IV groups followed by the SG, SGV and SGVF groups. These histological findings showed good correspondence with the clinical findings and results of the $\mu \mathrm{CT}$ analysis and, therefore, underscored the suitability of the present rat model for examining MRSA-induced osteomyelitis. In addition, in all animals, formation of a thin bony lamella around the SG-coated pins was noted, which displayed direct bone-biomaterial contact without intervening soft tissue. Therefore, this confirmed the previously described osteoconductive properties of the coating (Ducheyne, 1985; Ducheyne and Qiu, 1999; Radin et al., 2005, Qu et al., 2015b), which were not altered by dual-drug integration and even facilitated attracting osteogenic cells and subsequent bone formation in the presence of active infection, inflammation and osteomyelitis. In combination with the $\mu \mathrm{CT}$ results, the histological findings showed that both SGV and SGVF had an inhibitory effect on the development of osteomyelitis, reactive bone remodelling or osteolysis. Similar findings showing a less pronounced inflammatory reaction based on the diagnostic criteria for osteomyelitis (Herrmann et al., 2005; Illgner et al., 2013) were reported when using intramedullary rods with gentamycin coating to reduce $S$. aureus-induced osteomyelitis in rats in combination with a transverse incision technique and comparing these coated rods to uncoated controls or systemic gentamycin administration (Lucke et al., 2003a; 2003b; 2005).

\section{Immunohistochemical analysis}

The results of the $S$. aureus staining (Fig. 5a) revealed a significantly lower infiltration of the medullary canal with MRSA after 4 weeks of implantation when SGVF- and SGV-coated rods were utilised as compared to the SG and Vanc IV groups. This antimicrobial effect was stronger for the SGVF than for the SGV group. The findings for SGV group agreed with those of previous studies (Adams et al., 2009; Antoci et al., 2007), demonstrating the antibacterial effectiveness of SGV for inhibiting S. aureus-induced osteomyelitis. The results of the $S$. aureus staining for the SGVF group corroborated previous in vitro results (Bhattacharyya et al., 2014) and, furthermore, demonstrated the superior antibacterial effect on MRSA of the SGVF as compared to the SGV, which most likely was due to the prevention of biofilm formation (Pammi et al., 2011).

The early stages of osteoblast differentiation and extracellular matrix formation are associated with high expression levels of COL I. The post-proliferative phase is characterised by the expression of ALP. OC and BSP expression is characteristic of the terminally differentiated osteoblasts, which are actively involved in extracellular matrix mineralisation (Owen et al., 1990). In the present experimental setup, significant differences in the expression levels of these various osteogenic markers were mainly observed in osteoblasts. As such, lower ALP expression (Fig. 5c) was noted at 4 weeks in the SGV and SGVF groups when compared to the SG and Vanc IV groups. The same was true for the SGVF group at 2 weeks. This is indicative of more bone formation and remodelling, 
which was observed in the SG and Vanc IV groups.

Considerably more BSP (Fig. 5d) and OC expression (Fig. 5e) was observed in osteoblasts and mineralised bone matrix in the Vanc IV and SG groups, with expression in the SGVF group being the lowest, which is indicative of early reactive bone formation, matrix mineralisation and remodelling. Taken together, the strongest osteogenic marker expression was present in the Vanc IV and SG groups, while the SGV and SGFV groups only displayed low expression patterns, being the lowest in the SGFV group. Consequently, the findings of the immunohistochemical analysis of osteogenic marker expression seemed to reveal more reactive bone remodelling activity in the Vanc IV and SG groups when compared to the SGV and SGVF groups. The difference observed between the SGV and SGVF groups may be due to an even stronger inhibitory effect of the SGVF on MRSA-induced osteomyelitis and, thus, less reactive bone formation. On the other hand, Unnanuntana et al. (2009) have reported an inhibitory effect of farnesol on osteoblast spreading on Ti-6Al-4V alloy, when $3 \mathrm{mmol} / \mathrm{L}(667 \mu \mathrm{g} / \mathrm{mL})$ and $30 \mathrm{mmol} / \mathrm{L}(6,670 \mu \mathrm{g} / \mathrm{mL})$ farnesol concentrations are applied, while with a $0.3 \mathrm{mmol} / \mathrm{L}$ solution, osteoblast spreading and cytoskeletal arrangement remain unaffected. A $0.3 \mathrm{mmol} / \mathrm{L}$ solution contains $66.7 \mu \mathrm{g}$ farnesol/mL, while the SG coatings used in the present study released $12-13 \mu \mathrm{g}$ farnesol $/ \mathrm{mL} / \mathrm{d}$, i.e. a much lower concentration. In addition, a more recent in vivo study in mice has shown that administration of a $1 \%$ farnesol-containing diet marginally prevents ovariectomy-induced bone loss and enhances bone mass gain in growing C57BL/6J mice (Cho et al., 2013). These findings corroborate the observation of bone formation with uninhibited osteoblast function at the surface of the SGVF in vivo.

Vanc IV animals displayed the strongest inflammatory signs, the largest amount of necrotic bone and osseous destruction, with also the osseous microanatomy of the contralateral leg being affected, and, thus, a poorer outcome than the control animals having the SG implant. van Opstal et al. (2016) have reported that intravenous administration of vancomycin in rodents leads to an altered humoral immunity with a reduced $\operatorname{IgA}$, IgG and IgM response to a bacterial challenge associated with an implant. This is in addition to an altered intestinal microbiota. It can be suspected that the intravenous vancomycin administration, whose efficacy was not sufficiently high for being able to eradicate the infection and thereby reduce the inflammatory response in the present study, may have decreased the systemic humoral response and capacity for fighting the infection in these animals. In the control animals with the SG implant, although there were no drugs administered that could have eradicated the infection, the humoral immunity was most likely unaltered, which may have led to the slightly better outcome as compared to the Vanc IV group. As emphasised by van Obstal et al. (2016), the possible negative effect of intravenous vancomycin administration on the humoral immunity merits further investigation with respect to implant-related infections, especially in elderly patients.

Since the present study was designed as a first feasibility study, the number of laboratory animals approved for experimental use was limited, which imposed limitations to the power of the histological and immunohistochemical results. However, collectively the clinical findings as well as results of the $\mu \mathrm{CT}$, histological and immunohistochemical analyses revealed the most pronounced MRSA tissue infiltration, inflammatory changes and osteomyelitisrelated destruction of the osseous microanatomy in the Vanc IV and SG groups, while excellent preservation of the osseous microarchitecture was demonstrated for the SGV and SGVF groups, with the SGVF suppressing MRSA tissue infiltration to the largest degree in combination with displaying the lowest reactive bone-remodelling activity.

For advancing the presented dual drug delivery from SG coatings to the clinic, the beneficial effect of the SGVF on MRSA tissue infiltration and on reactive bone remodelling needs to be confirmed at later time points, such as 3 and 6 months. As a result, a large animal study in sheep is warranted, which also includes studying longer time points. To this end, a suitable sheep infection model, which also facilitates analysis of biofilm formation on the SGcoated intramedullary rods as well as characterisation of vancomycin and farnesol serum levels, has been recently developed (Qu et al., 2014).

\section{Conclusion}

The present study examined the efficacy of a dual local drug-release concept with respect to mitigation of infection and osteomyelitis in vivo and validated this concept. In addition, an experimental model was established for examining the efficacy of other therapeutic molecule combinations, such as linezolid and farnesol, against $S$. aureus strains resistant to vancomycin (Hiramatsu et al., 1997a; Hiramatsu et al., 1997b; Sieradzki et al., 1999). While both the SGVF and SGV facilitated excellent preservation of the osseous microarchitecture, SGVF may possess a slightly higher potency for suppressing MRSA infiltration. Contrasting with these positive outcomes, the immunohistochemical analysis revealed considerably more reactive bone formation and bone remodelling activity in the Vanc IV and SG group when compared to the SGV and SGVF groups. The next step for advancing the concept of dual drug delivery from SG coatings to the clinic, confirming the promising effect of the SGVF on reactive bone remodelling and suppressing MRSA infiltration, is a study with longer time points in a larger-animal species. 


\section{Acknowledgments}

The authors would like to thank Larry Fisher for providing the LF-84 antibody. The funding by the US Army (contract \#W81XWH-10-2-0156) is gratefully acknowledged. The authors also thank Ms. A. Kopp and Ms. M. Kratz for their technical assistance and the Veteran's Affairs for providing additional lab space.

\section{References}

Adams CS, Antoci V, Harrison G, Patal P, Freeman TA, Shapiro IM, Parvizi J, Hickok NJ, Radin S, Ducheyne P (2009) Controlled release of vancomycin from thin sol-gel films on implant surfaces successfully controls osteomyelitis. J Orthop Res 27: 701-709.

Adams K, Couch L, Cierny G, Calhoun J, Mader JT (1992) In vitro and in vivo evaluation of antibiotic diffusion from antibiotic-impregnated polymethylmethacrylate beads. Clin Orthop Relat Res 278: 244-252.

Anagnostakos K, Wilmes P, Schmitt E, Kelm J (2009) Elution of gentamicin and vancomycin from polymethylmethacrylate beads and hip spacers in vivo. Acta Orthop 80: 193-197.

Antoci V, Adams CS, Hickok NJ, Shapiro IM, Parvizi J (2007) Vancomycin bound to Ti rods reduces periprosthetic infection: preliminary study. Clin Orthop Relat Res 461: 88-95.

Antoci V, Adams CS, Parvizi J, Davidson HM, Composto RJ, Freeman TA, Wickstrom E, Ducheyne P, Jungkind D, Shapiro IM, others (2008) The inhibition of Staphylococcus epidermidis biofilm formation by vancomycin-modified titanium alloy and implications for the treatment of periprosthetic infection. Biomaterials 29: 4684-4690.

Arens D, Wilke M, Calabro L, Hackl S, Zeiter S, Zderic I, Richards RG, Moriarty TF (2015) A rabbit humerus model of plating and nailing osteosynthesis with and without Staphylococcus aureus osteomyelitis. Eur Cell Mater 30: 148-162.

Aughenbaugh W, Radin S, Ducheyne P (2001) Silica sol-gel for the controlled release of antibiotics. II. The effect of synthesis parameters on the in vitro release kinetics of vancomycin. J Biomed Mater Res 57: 321-326.

Avery L, Bennett R, Brinsley-Rainisch K, Boyter M, Coffin N, Deshpande S, Dudeck MA, Edwards JR, Fuller S, Maciejewski R, others (2015) National and state healthcare-associated infections progress report. CDC Stacks.

Beckmann J, Kees F, Schaumburger J, Kalteis T, Lehn N, Grifka J, Lerch K (2007) Tissue concentrations of vancomycin and moxifloxacin in periprosthetic infection in rats. Acta Orthop 78: 766-773.

Bhattacharyya S, Agrawal A, Knabe C, Ducheyne P (2014) Sol-gel silica controlled release thin films for the inhibition of methicillin-resistant Staphylococcus aureus. Biomaterials 35: 509-517.
Bouxsein ML, Boyd SK, Christiansen BA, Guldberg RE, Jepsen KJ, Müller R (2010) Guidelines for assessment of bone microstructure in rodents using micro-computed tomography. J Bone Miner Res 25: 1468-1486.

Braem A, Van Mellaert L, Mattheys T, Hofmans D, De Waelheyns E, Geris L, Anne J, Schrooten J, Vleugels J (2014) Staphylococcal biofilm growth on smooth and porous titanium coatings for biomedical applications. J Biomed Mater Res A 102: 215-224.

Braunschweig R, Bergert H, Kluge R, Tiemann AH (2011) Bildgebende Diagnostik bei Osteitis/ Osteomyelitis und Gelenkinfekten. Z Orthop Unfall 149: 436-448.

Cancienne JM, Burrus MT, Weiss DB, Yarboro SR (2015) Applications of local antibiotics in orthopedic trauma. Orthop Clin North Am 46: 495-510.

Catauro M, Papale F, Roviello G, Ferone C, Bollino F, Trifuoggi M, Aurilio C (2014) Synthesis of SiO and $\mathrm{CaO}$ rich calcium silicate systems via sol-gel process: bioactivity, biocompatibility, and drug delivery tests. J Biomed Mater Res A 102: 3087-3092.

Centers for Disease Control and Prevention C (2004) Vancomycin-resistant Staphylococcus aureusNew York, 2004. MMWR Morb Mortal Wkly Rep 53: 322-323.

Cho SW, An JH, Park H, Yang JY, Choi HJ, Kim SW, Park YJ, Kim SY, Yim M, Baek WY (2013) Positive regulation of osteogenesis by bile acid through FXR. J Bone Miner Res 28: 2109-2121.

Constantino JA, Delgado-Rastrollo M, PachaOlivenza MA, Perez-Giraldo C, Quiles M, GonzalezMartin ML, Gallardo-Moreno AM (2016) In vivo bactericidal efficacy of farnesol on Ti6Al4V implants. Rev Esp Cir Ortop Traumatol 60: 260-266.

Ducheyne P (1985) Bioglass coatings and bioglass composites as implant materials. J Biomed Mater Res A 19: 273-291.

Ducheyne P, Qiu Q (1999) Bioactive ceramics: the effect of surface reactivity on bone formation and bone cell function. Biomaterials 20: 2287-2303.

Engelke K, Karolczak M, Lutz A, Seibert U, Schaller S, Kalender W (1999) Micro-CT. Technology and application for assessing bone structure. Der Radiologe 39: 203-212.

Escribano LM, Gabriel LC, Villa E, Navarro J (1987) Endogenous peroxidase activity in human cutaneous and adenoidal mast cells. J Histochem Cytochem 35: 213-220.

Fölsch C, Federmann M, Lakemeier S, Kuehn KD, Kittinger C, Kerwat M, Fuchs-Winkelmann S, Paletta Ju, rgen RJ, Roessler PP (2016) Systemic antibiotic therapy does not significantly improve outcome in a rat model of implant-associated osteomyelitis induced by methicillin susceptible Staphylococcus aureus. Arch Orthop Trauma Surg 136: 585-592.

Fraimow HS (2009) Systemic antimicrobial therapy in osteomyelitis. Semin Plast Surg 23: 90-99.

Freeman TA, Patel P, Parvizi J, Antoci V Jr, Shapiro IM (2009) Micro-CT analysis with multiple thresholds allows detection of bone formation and resorption 
during ultrasound-treated fracture healing. J Orthop Res 27: 673-679.

Fuchs T, Stange R, Schmidmaier G, Raschke MJ (2011) The use of gentamicin-coated nails in the tibia: preliminary results of a prospective study. Arch Orthop Trauma Surg 131: 1419-1425.

GerR (1977) Muscle transposition for treatment and prevention of chronic post-traumatic osteomyelitis of the tibia. JBJS 59: 784-791.

Gristina AG, Costerton JW (1985) Bacterial adherence to biomaterials and tissue. The significance of its role in clinical sepsis. J Bone Joint Surg Am 67: 264-273.

Gristina AG, Oga M, Webb LX, Hobgood CD (1985) Adherent bacterial colonization in the pathogenesis of osteomyelitis. Science 228: 990-993.

Helbig L, Simank HG, Lorenz H, Putz C, Wölfl C, Suda AJ, Moghaddam A, Schmidmaier G, Guehring $\mathrm{T}$ (2014) Establishment of a new methicillin resistant Staphylococcus aureus animal model of osteomyelitis. Int Orthop 38: 891-897.

Herrmann M, Becker K, von Eiff C, Fegeler W, Frommelt L, Gärtner B (2005) MiQ 18. Infektionen der Knochen und des Knorpels. Teil I q II. Qualitätsstandards in der mikrobiologischinfektiologischen Diagnostik. Urban \& Fischer, Munich.

Hiramatsu K, Aritaka N, Hanaki H, Kawasaki S, Hosoda Y, Hori S, Fukuchi Y, Kobayashi I (1997a) Dissemination in Japanese hospitals of strains of Staphylococcus aureus heterogeneously resistant to vancomycin. Lancet 350: 1670-1673.

Hiramatsu K, Hanaki H, Ino T, Yabuta K, Oguri T, Tenover FC (1997b) Methicillin-resistant Staphylococcus aureus clinical strain with reduced vancomycin susceptibility. J Antimicrob Chemother 40: 135-136.

Illgner U, Krenn V, Osada N, Bause L (2013) [Histopathology and microbiology of joint infections: extension of diagnostic safety in patients with chronic polyarthritis]. Z Rheumatol 72: 709-713.

Jabra-Rizk MA, Meiller TF, James CE, Shirtliff ME (2006) Effect of farnesol on Staphylococcus aureus biofilm formation and antimicrobial susceptibility. Antimicrob Agents Chemother 50: 1463-1469.

Kaneko M, Togashi N, Hamashima H, Hirohara M, Inoue Y (2011) Effect of farnesol on mevalonate pathway of Staphylococcus aureus. J Antibiot (Tokyo) 64: 547-549.

Kaplow LS (1955) A histochemical procedure for localizing and evaluating leukocyte alkaline phosphatase activity in smears of blood and marrow. Blood 10: 1023-1029.

Kavanagh KT, Abusalem S, Calderon LE (2017) The incidence of MRSA infections in the United States: is a more comprehensive tracking system needed? Antimicrob Resist Infect Control 6: 34. DOI: 10.1186/s13756-017-0193-0.

Khardori N, Yassien M (1995) Biofilms in devicerelated infections. Biotechnol J 15: 141-147.
Kim C, Hesek D, Lee M, Mobashery S (2018) Potentiation of the activity of $\beta$-lactam antibiotics by farnesol and its derivatives. Bioorg Med Chem Lett 28: 642-645.

Knabe C, Kraska B, Koch C, Gross U, Zreiqat H, Stiller M (2006) A method for immunohistochemical detection of osteogenic markers in undecalcified bone sections. Biotech Histochem 81: 31-39.

Kollef MH (2007) Limitations of vancomycin in the management of resistant staphylococcal infections. Clin Infect Dis 45: S191-S195.

Lalidou F, Kolios G, Drosos GI (2014) Bone infections and bone graft substitutes for local antibiotic therapy. Surg Technol Int 24: 353-362.

Landis JR, Koch GG (1977) An application of hierarchical kappa-type statistics in the assessment of majority agreement among multiple observers. Biometrics 33: 363-374.

Lemaire S, Olivier A, Van Bambeke F, Tulkens PM, Appelbaum PC, Glupczynski Y (2008) Restoration of susceptibility of intracellular methicillin-resistant Staphylococcus aureus to beta-lactams: comparison of strains, cells, and antibiotics. Antimicrob Agents Chemother 52: 2797-2805.

Lew DP, Waldvogel FA (2004) Osteomyelitis. Lancet 364: 369-379.

Lorensen WE, Cline HE (1987) Marching cubes: a high resolution 3D surface construction algorithm. ACM SIGGRAPH Computer Graphics: 163-169. DOI: 10.1145/37402.37422.

Lucke M, Schmidmaier G, Sadoni S, Wildemann B, Schiller R, Haas NP, Raschke M (2003a) Gentamicin coating of metallic implants reduces implant-related osteomyelitis in rats. Bone 32: 521-531.

Lucke M, Schmidmaier G, Sadoni S, Wildemann B, Schiller R, Stemberger A, Haas NP, Raschke M (2003b) A new model of implant-related osteomyelitis in rats. J Biomed Mater Res B Appl Biomater 67: 593-602.

Lucke M, Wildemann B, Sadoni S, Surke C, Schiller R, Stemberger A, Raschke M, Haas NP, Schmidmaier G (2005) Systemic versus local application of gentamicin in prophylaxis of implant-related osteomyelitis in a rat model. Bone 36: 770-778.

Mader JT, Calhoun J (1996) Bone, joint, and necrotizing soft tissue infections. Medical Microbiology 4th edition. Editor: Baron S. Univ of Texas Medical Branch. Galveston (TX). ISBN: 0-9631172.

Massias L, Dubois C, de Lentdecker P, Brodaty O, Fischler M, Farinotti R (1992) Penetration of vancomycin in uninfected sternal bone. Antimicrob Agents Chemother 36: 2539-2541.

Mathes SJ, Alpert BS, Chang N (1982) Use of the muscle flap in chronic osteomyelitis: experimental and clinical correlation. Plast Reconstr Surg 69: 815828.

McGovern JA, Griffin M, Hutmacher DW (2018) Animal models for bone tissue engineering and modelling disease. Dis Model Mech 11: dmm033084. DOI: $10.1242 / \mathrm{dmm} .033084$. 
Mecikoglu M, Saygi B, Yildirim Y, Karadag-Saygi E, Ramadan SS, Esemenli T (2006) The effect of proteolytic enzyme serratiopeptidase in the treatment of experimental implant-related infection. JBJS 88: 1208-1214.

Minkin C (1982) Bone acid phosphatase: tartrateresistant acid phosphatase as a marker of osteoclast function. Calcif Tissue Int 34: 285-290.

Muhonen V, Kujala S, Vuotikka A, Aäritalo V, Peltola T, Areva S, Närhi T, Tuukkanen J (2009) Biocompatibility of sol-gel-derived titania-silica coated intramedullary NiTi nails. Acta Biomater 5: 785-793.

Mulisch M, Welsch U (2015) RomeisMikroskopische Technik. Springer-Verlag. DOI: 10.1007/978-3-642-55190-1.

Nishimura K, Shindo S, Movila A, Kayal R, Abdullah A, Savitri IJ, Ikeda A, Yamaguchi T, Howait M, Al-Dharrab A, others (2016) TRAP-positive osteoclast precursors mediate ROS/NO-dependent bactericidal activity via TLR4. Free Radic Biol Med 97: 330-341.

Norden CW (1988) Lessons learned from animal models of osteomyelitis. Rev Infect Dis 10: 103-110.

Owen TA, Aronow M, Shalhoub V, Barone LM, Wilming L, Tassinari MS, Kennedy MB, Pockwinse S, Lian JB, Stein GS (1990) Progressive development of the rat osteoblast phenotype in vitro: reciprocal relationships in expression of genes associated with osteoblast proliferation and differentiation during formation of the bone extracellular matrix. J Cell Physiol 143: 420-430.

Pammi M, Liang R, Hicks JM, Barrish J, Versalovic J (2011) Farnesol decreases biofilms of Staphylococcus epidermidis and exhibits synergy with nafcillin and vancomycin. Pediatr Res 70: 578-583.

Parsons B, Strauss E (2004) Surgical management of chronic osteomyelitis. Am J Surg 188: 57-66.

Probst RJ, Lim JM, Bird DN, Pole GL, Sato AK, Claybaugh JR (2006) Gender differences in the blood volume of conscious Sprague-Dawley rats. J Am Assoc Lab Anim Sci 45: 49-52.

Qu H, Bhattacharyya S, Ducheyne P (2015a) Silicon oxide based materials for controlled release in orthopedic procedures. Adv Drug Deliv Rev 94: 96-115.

Qu H, Knabe C, Burke M, Radin S, Garino J, Schaer T, Ducheyne P (2014) Bactericidal micron-thin sol-gel films prevent pin tract and periprosthetic infection. Mil Med 179: 29-33.

Qu H, Knabe C, Radin S, Garino J, Ducheyne P (2015b) Prevention of pin tract infection in external fixation using bactericidal micron-thin SG films. Biomaterials 62: 95-105.

Radin S, Bhattacharyya S, Ducheyne P (2013) Nanostructural control of the release of macromolecules from silica sol-gels. Acta Biomater 9: 7987-7995.

Radin S, Ducheyne P (2007) Controlled release of vancomycin from thin sol-gel films on titanium alloy fracture plate material. Biomaterials 28: 1721-1729.
Radin S, Ducheyne P, Kamplain T, Tan BH (2001) Silica sol-gel for the controlled release of antibiotics. I. Synthesis, characterization, and in vitro release. J Biomed Mater Res 57: 313-320.

Radin S, El-Bassyouni G, Vresilovic EJ, Schepers E, Ducheyne P (2005) In vivo tissue response to resorbable silica xerogels as controlled-release materials. Biomaterials 26: 1043-1052.

Radin S, Falaize S, Lee MH, Ducheyne P (2002) In vitro bioactivity and degradation behavior of silica xerogels intended as controlled release materials. Biomaterials 23: 3113-3122.

Reizner W, Hunter JG, O'Malley NT, Southgate RD, Schwarz EM, Kates SL (2014) A systematic review of animal models for Staphylococcus aureus osteomyelitis. Eur Cell Mater 27: 196-212.

Rissing JP (1990) Animal models of osteomyelitis. Knowledge, hypothesis, and speculation. Infect Dis Clin North Am 4: 377-390.

Robert-Koch-Institut (2015) Eigenschaften, Häufigkeit und Verbreitung von MRSA in mDeutschland - Update 2013/2014

Royston P (1995) Remark AS R94: a remark on algorithm AS 181: the W-test for normality. JSTOR 44: 547-551.

Santos EM, Radin S, Ducheyne P (1999) Sol-gel derived carrier for the controlled release of proteins. Biomaterials 20: 1695-1700.

Sarve H, Lindblad J, Borgefors G, Johansson CB (2011) Extracting 3D information on bone remodeling in the proximity of titanium implants in SR $\mu \mathrm{CT}$ image volumes. Comput Methods Programs Biomed 102: 25-34.

Schierholz JM, Morsczeck C, Brenner N, König DP, Yücel N, Korenkov M, Neugebauer E, Rump AFE, Waalenkamp G, Beuth J, G Pulverer, S Arens (2004) [Special aspects of implant-associated infection in orthopedic surgery. from the pathophysiology to custom-tailored prevention strategies]. Orthopade 33: 397-404.

Schmidmaier G, Lucke M, Wildemann B, Haas NP, Raschke M (2006) Prophylaxis and treatment of implant-related infections by antibiotic-coated implants: a review. Injury 37: S105-S112.

Schmidt HGK, Diefenbeck M, Krenn V, Abitzsch D, Militz M, Tiemann AH, Haustedt N, Gückel P, Bühler M, Gerlach U-J (2014) [Classification of haematogenous and post-traumatic osteomyelitis]. Z Orthop Unfall 152: 334-342.

Schnettler R, Steinau H-U (2004) Septische Knochenchirurgie. In: Septische Knochenchirurgie. Thieme.

Schwameis E, Abdolvahab F, Wurnig C (1996) [Osteomyelitis. Clinical aspects, diagnosis and therapy]. Radiologe 36: 823-833.

Sganga G, Tascini C, Sozio E, Colizza S (2017) Early recognition of methicillin-resistant Staphylococcus aureus surgical site infections using risk and protective factors identified by a group of Italian surgeons through Delphi method. World J Emerg Surg 12: 25. DOI: 10.1186/s13017-017-0136-3. 
Sheehan E, McKenna J, Mulhall KJ, Marks P, McCormack D (2004) Adhesion of Staphylococcus to orthopaedic metals, an in vivo study. J Orthop 22: 39-43.

Sieradzki K, Roberts RB, Haber SW, Tomasz A (1999) The development of vancomycin resistance in a patient with methicillin-resistant Staphylococcus aureus infection. N Engl J Med 340: 517-523.

Spagnolo N, Greco F, Rossi A, Ciolli L, Teti A, Posteraro P (1993) Chronic staphylococcal osteomyelitis: a new experimental rat model. Infect Immun 61: 5225-5230.

Speziale P, Pietrocola G, Foster TJ, Geoghegan JA (2014) Protein-based biofilm matrices in Staphylococci. Front Cell Infect Microbiol 4: 171. DOI: 10.3389/ fcimb.2014.00171.

Stemberger A, Grimm H, Bader F, Rahn HD, Ascherl R (1997) Local treatment of bone and soft tissue infections with the collagen-gentamicin sponge. Eur J Surg Suppl: 17-26.

Stewart PS (2002) Mechanisms of antibiotic resistance in bacterial biofilms. Int J Med Microbiol 292: 107-113.

Thammavongsa V, Kim HK, Missiakas D, Schneewind O (2015) Staphylococcal manipulation of host immune responses. Nat Rev Microbiol 13: 529-543.

Tiemann A, Hofmann GO, Krukemeyer MG, Krenn V, Langwald S (2014) Histopathological Osteomyelitis Evaluation Score (HOES) - an innovative approach to histopathological diagnostics and scoring of osteomyelitis. GMS Interdiscip Plast Reconstr Surg DGPW 3: Doc08. DOI: 10.3205/iprs000049.

Tiemann AH (2017) Akute und chronische exogene Osteomyelitis langer Röhrenknochen des Erwachsenen. Leitlinien der Deutschen Gesellschaft für Unfallchirurgie.

Unnanuntana A, Bonsignore L, Shirtliff ME, Greenfield EM (2009) The effects of farnesol on Staphylococcus aureus biofilms and osteoblasts: an in vitro study. J Bone Joint Surg Am 91: 2683. DOI: 10.2106/JBJS.H.01699.

van Opstal E, Kolling GL, Moore JH, Coquery CM, Wade NS, Loo WM, Bolick DT, Shin JH, Erickson LD, Warren CA (2016) Vancomycin treatment alters humoral immunity and intestinal microbiota in an aged mouse model of Clostridium difficile infection. J Infect Dis 214: 130-139.

Vester H, Wildemann B, Schmidmaier G, Stöckle U, Lucke M (2010) Gentamycin delivered from a PDLLA coating of metallic implants: in vivo and in vitro characterisation for local prophylaxis of implantrelated osteomyelitis. Injury 41: 1053-1059.

Waldvogel FA, Medoff G, Swartz MN (1970) Osteomyelitis: a review of clinical features, therapeutic considerations and unusual aspects. N Engl J Med 282: 198-206.

Walter G, Kemmerer M, Kappler C, Hoffmann R (2012) Treatment algorithms for chronic osteomyelitis. Dtsch Arztebl International 109: 257-264.
Wancket LM (2015) Animal models for evaluation of bone implants and devices: comparative bone structure and common model uses. Vet Pathol 52: 842-850.

Widaa A, Claro T, Foster TJ, O'Brien FJ, Kerrigan SW (2012) Staphylococcus aureus protein A plays a critical role in mediating bone destruction and bone loss in osteomyelitis. PLoS One 7: e40586. DOI: 10.1371/journal.pone.0040586.

Williams TW (1941) Alizarin red S and toluidine blue for differentiating adult or embryonic bone and cartilage. Stain Technol 16: 23-25.

Witte W, Braulke C, Cuny C, Heuck D, Kresken M (2001) Changing pattern of antibiotic resistance in methicillin-resistant Staphylococcus aureus from German hospitals. Infect Control Hosp Epidemiol 22: 683-686.

Yeom H, Blanchard S, Kim S, Zunt S, Chu T-MG (2008) Correlation between micro-computed tomography and histomorphometry for assessment of new bone formation in a calvarial experimental model. J Craniofac Surg 19: 446-452.

\section{Discussion with Reviewers}

Martijn Riool: Can you make any assumption regarding the effect of cells growing on the implant coating and the release kinetics? Since the implant should be integrated, the coating will be covered by cells. Would this stop release and hinder treatment of a late infection?

Authors: The coating materials in which the molecules were incorporated were biocompatible, resorbable materials. Upon implantation, the extracellular matrix material that formed on the films did not impede antibiotics release and transport to the bacteria (as shown in the present study). Late infections can arise 9 months or longer after surgery. At such time, the coatings will be long gone.

Bill Walsh: How translatable will the results be in a large-animal model? Will the release kinetics potentially have to be modified for different anatomical sites or species?

Authors: The specifics of how to advance the concept of controlled delivery of antibiotics from SG thin films, not just to a larger-animal model, but also to the clinic varies depending on intended use or indication. The quantity of released antibiotics and duration of release cannot be rigidly set. Moreover, it is also important to consider that the SG-processing technology platform confers major flexibility, as it is described e.g. by Qu et al. (2015a): "In fact, sol gels can be made in adherent thin films with a thickness varying between 0.2 and $5 \mu \mathrm{m}$ and contain various amounts of antibiotics. Sol gel processing also lends itself very well to producing particles from nano to micron size. All forms can be made with a variety of release kinetics". 
The key questions for a successful clinical use are: i) is the antibiotic damaged during incorporation in the carrier? (the answer is no: bactericidal functionality is unaffected)

ii) can sufficient antibiotics be delivered in a sustained fashion for the putative treatment duration?

This second question can be answered affirmatively by designing implants and implant procedures whereby delivery from thin films can conceivably be complemented by delivery from co-located particles.

To elaborate on the flexibility of the SG technology, for the sheep study that is mentioned in the present manuscript, thin films have been designed with concentrations of antibiotic close to the metallic implant interface different from the ones at the outer film surface. Thereby, targeted release rates were achieved. Qu et al. (2015b) designed a 3-month release of a bactericidal molecule from films on percutaneous pins of external fracture-fixation devices with the goal of preventing bacterial ingress over the duration that the pins stay in place.

Editor's note: The Scientific Editor responsible for this paper was Fintan Moriarty. 